\title{
Ontogenetic Changes in the Cyclic Adenosine 3',5'-monophosphate- stimulatable Phosphorylation of Cat Visual Cortex Proteins, Particulary of Microtubule-associated Protein 2 (MAP 2): Effects of Normal and Dark Rearing and of the Exposure to Light ${ }^{1}$
}

\author{
CHIYE AOKI ${ }^{2}$ AND PHILIP SIEKEVITZ \\ Laboratory of Cell Biology, The Rockefeller University, New York, New York, 10021
}

\begin{abstract}
Based on a theory that a norepinephrine-stimulated cascade of events resulting in an increase of intracellular cyclic adenosine $3^{\prime}, 5^{\prime}$-monophosphate (CAMP) modulates the state of plasticity for the receptive field property of visual cortical neurons, we have followed the ontogenetic changes in CAMPstimulated phosphorylation of proteins in whole homogenates obtained from developing visual cortices of cats. In vitro phosphorylation was assayed with and without CAMP and the CAMP-dependent protein kinase, and the phosphoproteins separated by sodium dodeycl sulfate-polyacrylamide gel electrophoresis were counted for ${ }^{32} \mathrm{P}$ incorporated from $\left[\gamma^{32}\right.$ P]ATP. It was found that the regulatory subunits of the cAMP-dependent protein kinase are present and fully active by birth, whereas the synapsin content increases at a rate concomitant with synaptogenesis. These ontogenetic developments are not influenced by dark rearing (DR) from birth, a procedure which postpones the onset of the critical period (CP) for plasticity. By contrast, the cAMP-stimulatable phosphorylation of microtubule-associated protein 2 (MAP 2), which under normal rearing conditions increases from birth to the second month, is strongly modulated by the presence of light in the environment. After DR for various periods, kittens were subsequently exposed to light so as to trigger the onset of the CP that had been postponed. A few hours of light were sufficient to cause a large increase in the in vitro phosphorylation of MAP 2. This effect is not observed in the auditory cortex or the lateral geniculate nucleus of the same animals, or in the visual cortex of normally reared cats which were then dark reared in adulthood. But this effect was seen in the visual cortices of cats following 5 months of DR from birth, animals which by chronological age have passed the $C P$, presumably because the onset of the $C P$ was extended by the DR procedure. The CAMP-dependent phosphorylation of MAP 2 (and its dephosphorylation) may be an important factor for determining the state of plasticity in the $\mathrm{CP}$ through its affecting the dendritic cytoskeletal organization involving tubulin and actin.
\end{abstract}

Received October 31, 1984; Revised February 4, 1985; Accepted February 8, 1985

${ }^{1}$ This work was supported by National Eye Institute Small Grant 1 R03EY04812 (to C. A.), Institutional Training Grant 5 T32 GM07524, and Grant NS-12726 (to P. S.), from the National Institutes of Health. The technical assistance of Marie Ledoux was very helpful in a part of this work.

${ }^{2}$ To whom correspondence should be addressed.
Beginning in 1963, Wiesel and Hubel (1963a, b) have reported evidence indicating that neuronal connectivity in the visual system, observable electrophysiologically as ocular dominance, could be modified by monocularly suturing one eye of the kitten during the early postnatal period (Wiesel and Hubel, 1963a, 1965; Hubel and Wiesel, 1970). This early period, termed the critical period (CP), was determined to span in kittens the first through the fourth month after birth. Much has been documented, using electrophysiological and neuroanatomical techniques, to further characterize the visual cortical plasticity in terms of the types of biases caused by the various modified visual environments (cf. reviews by Blakemore, 1974; Barlow, 1975; Movshon and Van Sluyters, 1981; Sherman and Spear, 1982). Our interest was to study the biochemical determinants of visual cortical plasticity by looking for biochemical events which correlated with the beginning and the end of the CP. We utilized the finding that the $\mathrm{CP}$ could be postponed for many months by dark rearing (Cynader et al., 1976; Timney et al. 1978, 1980; Cynader and Mitchell, 1980; Mower et al., 1981a, b) and that this dark-rearing effect of postponing the CP could be counteracted by a few hours of light exposure during the dark-rearing period (Mower et al., 1983). From these results, it can be interpreted that the onset of the CP is highly light dependent, but once triggered for the onset by a few hours of light, the plasticity for neuronal connectivity declines with the same time course as in normally reared animals.

We therefore raised kittens under three conditions: (a) normal light rearing, to observe the normal ontogenetic changes; $(b)$ rearing in complete darkness so as to alter the time course of the $\mathrm{CP}$; and (c) rearing in complete darkness, followed by short exposures to light just before sacrifice so as to observe the earliest biochemical events relevant to the beginning of the $\mathrm{CP}$. By these rearing manipulations, which shift the onset of the $\mathrm{CP}$, we hoped to observe concurring shifts in some biochemical parameters. Such biochemical events which were influenced by the rearing conditions, wo reasoned, might be the events relevant to determining the state of plasticity for the visual system.

We have based our biochemical experiments on the findings of Kasamatsu and co-workers and of others who have shown that lesion of the visual cortical noradrenergic terminals, obtained by perfusing the caudal cortex with 6-hydroxydopamine (6-OHDA), abolished the ocular dominance shift normally observed during the CP (Kasamatsu and Pettigrew, 1976, 1979; Kasamatsu et al., 1981a, b; Daw et al., 1981, 1983; Bear et al., 1983; Paradiso et al., 1983). This effect could be reversed by subsequent perfusion of the area with norepinephrine (NE) (Pettigrew and Kasamatsu, 1978; Kasamatsu et al., 1979, 1981a, b) or by cAMP (Kasamatsu, 1980). Furthermore, their results indicate that the NE-dependent event was mediated via $\beta$-adrenergic receptors to which are coupled the CAMP. synthesizing enzyme, adenylate cyclase (Kasamatsu, 1979). Thus, we have studied the ontogenetic changes of the following enzymes: 
(a) adenylate cyclase stimulatable by $\mathrm{NE} ;(b)$ cyclic nucleotide phosphodiesterase that hydrolyzes CAMP; (c) CAMP-dependent protein kinase that phosphorylates certain proteins; and $(d)$ these substrate proteins. The findings relating to points $a$ and $b$ will be reported elsewhere. Here, we present evidence about a specific phosphoprotein, microtubule-associated protein 2 (MAP 2), the phosphorylation of which, within the visual cortex, and not in the auditory cortex or the lateral geniculate nucleus (LGN), is highly dependent on the light-rearing conditions. A report of this research has appeared in abstract form (Aoki and Siekevitz, 1984).

\section{Materials and Methods}

Materials. Tris, morpholinoethanesulfate (MES), $\mathrm{MgCl}_{2}(4.9 \mathrm{M}$ solution), dithiothreitol $(\mathrm{DTT}), \mathrm{EGT} \wedge, \mathrm{c} \wedge \mathrm{MP}$, protein $\wedge(\mathrm{P}-6650)$, lactoperoxidase $(\mathrm{L}$ 2005), 3-isobutyl-1-methylxanthine (IBMX), bovine heart cAMP-dependent protein kinase (P-5511), 3', $3^{\prime}$-diaminobenzidine, ammonium persulfate, bromphenol blue, Coomassie blue, $N, N, N^{\prime}, N^{\prime}$-tetramethylethylenediamine, and Triton X-100 were all obtained from Sigma Chemical Co. Leupeptin was obtained from Vega Biochemicals, sodium dodecyl sulfate (SDS) (ultrapure) was from BDH Chemicals, bovine serum albumin fraction $V(B S A)$ was from Armour Pharmaceutical Co., and glycine and imidazole were from Aldrich Chemical Co. Affinity-purified lgG fraction of peroxidase-conjugated rabbit anti-mouse antiserum (no. 3315-3503) was from Jackson ImmunoResearch Laboratories, Inc., and affinity-purified lgG fraction of rabbit anti-mouse antiserum was from Jackson ImmunoResearch (no. 315-0503) and Cappel Laboratories (no. 0611-3152). [ $\left.\gamma^{32} \mathrm{P}\right] \mathrm{ATP}(1000$ to $3000 \mathrm{Ci} / \mathrm{mmol})$, ${ }^{125}$-protein $\mathrm{A}(70$ to $100 \mu \mathrm{Ci} / \mu \mathrm{g})$, and $\mathrm{Na}^{125}$ ( were obtained from new England Nuclear; ${ }^{32} \mathrm{P}$-8-azido-cAMP (8- $\mathrm{N}_{3}$-CAMP) (>22 Ci/mmol) was obtained from Schwartz/ Mann, Inc. and International Chemical and Nuclear Corp. XRP-5 and XRP-1 $x$-ray films were obtained from Kodak, and intensifying screens for development of autoradiograms were from DuPont. Acrylamide and bis-acrylamide were from Kodak; Hydrofluor was from National Diagnostics; and nitrocellulose paper BA85 $(0.45 \mu \mathrm{m}$ pore size) was from Schleicher and Schuell. Monoclonal antibodies for MAP 2 were gifts from Drs. G. Huber and A. Matus, Friedrich Miescher Institut (Basel, Switzerland) (Huber and Matus, 1984a), and clones AP 7, 13, and 14 against MAP 2 were gifts from Dr. L. Binder, Department of Biology, University of Virginia (Charlottesville, VA) (Caceres et. al., 1984a). Bovine MAP 2, purified by the method of Kim et al. (1979), was also a gift from Dr. Binder. Anti- $\alpha$-fodrin was proparcd by Dr. R. Carlin of this laboratory (Carlin et al., 1983). Postsynaptic densities from canine cerebral cortices were prepared by Dr. R. K. Carlin of this laboratory, according to the procedure of Cohen et al. (1977), as modified by Carlin et al. (1980).

Rearing of cats. All animals were reared by the staff of the Laboratory of Animal Research Center of Rockefeller University in accordance with the Guide for the Care and Use of Laboratory Animals. Pregnant cats were obtained from Quaker Farms or were mated at Rockefeller University. Normally reared kittens were reared with their mother cat in cages with overhead air filtration. Dark-reared kittens were put in light-tight wooden cages with their mother within a week after birth. Every light-tight cage was painted with water-impermeable paint to facilitate cleaning, and was connected to two coiled black ducts, one of which was attached to a motordriven fan to ensure proper ventilation within the cages. The cages were situated within a light-tight room, so that the staff members for animal care could open the boxes for cage cleaning and feeding without exposing the kittens to light. Every box was monitored for light leakage by placing $x$-ray films within transparent plastic cases within the cages. At the end of the dark-rearing period, the cats were either anesthetized immediately or exposed to the light in the room by opening the top of the cage. Thus, the animals did not leave the cage to become exposed to light.

Preparation of whole homogenatcs. Cats were sacrificed by first injecting with ketamine hydrochloride ( 20 to $30 \mathrm{mg} / \mathrm{kg}$ of body weight), and then by intravenous Nembutal until the corneal reflex was abolished. At this point, brains were dissected out within $3 \mathrm{~min}$ and placed in $0.32 \mathrm{M}$ sucrose $/ 1.0 \mathrm{mM}$ $\mathrm{NaHCO}_{3}, 6.5 \mathrm{~mm} \mathrm{MgCl}$ buffer $\left(\mathrm{pH} 7.0,4^{\circ} \mathrm{C}\right)$. Area 17 of the visual cortex, area $\mathrm{AC} 1$ of the auditory cortex, as well as the whole LGN (see Fig. 1) were homogenized at a concentration of $0.2 \mathrm{gm}$ of wet weight $/ \mathrm{ml}$ of the above buffer with the addition of $10 \mu \mathrm{g} / \mathrm{ml}$ of leupeptin (Toyo-oka et al., 1978; Baudry et al., 1981) using a Teflon-and-glass homogenizer (clearance, 0.05 to $0.10 \mathrm{~mm}$, Thomas no. $3431-535)$. DTT $(1.0 \mathrm{~mm}$ final concentration) was added to the homogenates, and 50 to $100 \mu$ aliquots of whole homogenates were frozen within $10 \mathrm{~min}$ from the time the homogenization began. Aliquots 2,4 , and $6 \mu$ l of homogenates were also processed for protein determination

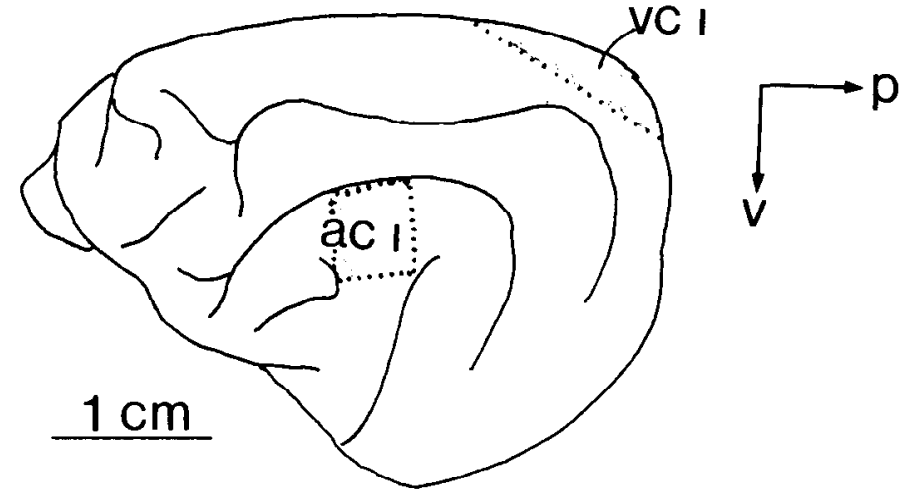

Figure 1. A schematic representation of the left hemisphere of the cat visual cortex demarking the regions used as sources of whole homogenates from primary visual cortex ( $v c i)$ and primary auditory cortex (aci). $v$, ventral; $p$, posterior. The lateral geniculate nucleus, not represented here, was localized by first finding the optic chiasm on the ventral surface of the brain and then tracing the optic tract toward the nucleus.

by the method of Lowry et al. (1951) and gave values ranging from 10 to 20 $\mathrm{mg} / \mathrm{ml}$.

Gel electrophoresis. SDS-gel electrophoresis was performed according to the discontinuous buffer system of Neville (1971) modified by Cohen et al., (1977). Gels were $2 \mathrm{~mm}$ thick and $30 \mathrm{~cm}$ wide $\times 24 \mathrm{~cm}$ long, and the total acrylamide in the separating gel varicd linearly from 5.6 to $17.3 \%$. The total acrylamide in the stacking gel was kept at $4.5 \%$. The pH's of lower reservoir/ separating gel buffer, upper reservoir buffer, and upper stacking gel buffer were, respeclively, 9.18, 8.64, and 6.10. Electrophoresis was carried out for 12 to $18 \mathrm{hr}$ at $125 \mathrm{~V}$. Gels were stained with $0.25 \%$ Coomassie blue in $50 \%$ methanol $/ 7 \%$ acetic acid, destained, mounted on Whatman 3MM paper, and dried under vacuum.

CAMP-dependent protein phosphorylation. The standard assay for phosphorylation of proteins by a CAMP-dependent protein kinase was performed by the method of Ueda et al. (1979). Each $100-\mu$ l assay mixture contained $50 \mathrm{mM}$ MES (pH 6.2), $10 \mathrm{~mm} \mathrm{MgCl} 2,1.0 \mathrm{~mm}$ DTT, $1.0 \mathrm{~mm} \mathrm{IBMX}, 10 \mu \mathrm{M}[\gamma$ $\left.{ }^{32} \mathrm{P}\right] \mathrm{ATP}(5 \mu \mathrm{Ci} / \mathrm{sample}), 0.2 \mathrm{mM}$ EGTA, and, when indicated, 8 units of bovine heart cAMP-dependent protein kinase and various concentrations of CAMP. Unless indicated otherwise, $100 \mu \mathrm{g}$ of protein from whole homogenates of the visual cortex, auditory cortex, or LGN werc suspended (with CAMP and exogenous kinase, if so indicated) in the buffer in the absence of ATP and were preincubated at $30^{\circ} \mathrm{C}$ for $60 \mathrm{sec}$. The reaction was started by adding ATP. After incubating at $30^{\circ} \mathrm{C}$ for $60 \mathrm{sec}$, the reaclion was terminated by adding $30 \mu \mathrm{l}$ of SDS-PAGE stop solution which contained, at a final concentration, $2 \%$ SDS, $3 \%$ mercaptoethanol, $7 \%$ glycerol, $0.08 \mathrm{M} \mathrm{Tris}-\mathrm{HCl}$ $(\mathrm{pH} 6.7)$, and $0.002 \%$ bromphenol blue. The samplesd were placed in a boiling water bath for $3 \mathrm{~min}$, cooled to room temperature, and the entire sample (100 $\mu \mathrm{g}$ of protein) was loaded onto SDS-gels for electrophoresis. To obtain autoradiograms, dried gels were exposed to XRP-5 and XRP-1 Xray films for 2 to 7 days with intensifying screens.

Photoaffinity labeling of the regulatory subunits of CAMP-dependent protein kinase. The procedure for labeling was that of Pomerantz et al. (1980), using ${ }^{32} \mathrm{P}-8-\mathrm{N}_{3}$-CAMP (22 to $87 \mathrm{Ci} / \mathrm{mmol}$ ). The reaction mixture contained $100 \mu \mathrm{g}$ of protein of whole homogenates in a volume of $100 \mu \mathrm{l}$ of the buffer system identical to that used for phosphorylation and including 10 $\mu \mathrm{M}$ ATP, with varying concentrations of ${ }^{32} \mathrm{P}-8-\mathrm{N}_{3}$-CAMP ranging from $10^{-9} \mathrm{M}$ to $10^{-6} \mathrm{M}$. CAMP $\left(10^{-3} \mathrm{M}\right)$ was also added to some tubes to discriminate specific fron nonspecific binding. The reaction mixture was incubated in the dark for $1 \mathrm{hr}$ at $4^{\circ} \mathrm{C}$ in $1.5-\mathrm{ml}$ Eppendorf tubes and then were transferred into shallow parafilm-lined receptacles on ice water so as to maximize the surface area for irradiation. The $100-\mu l$ reaction mixture was irradiated with a UV lamp (Universial UV unit, Gelman Sciences, Inc., Model 5434) at a distance of $2 \mathrm{~cm}$. The samples were then electrophoresed on SDS-polyacrylamide gels as described above. The gels were stained, dried, and exposed to $x$-ray films with an intensifying screen to obtain autoradiograms.

Quantification of the radioactivity incorporated into protein bands of gels. ${ }^{32} \mathrm{P}$, either from $\left[\gamma^{32} \mathrm{P}\right] \mathrm{ATP}$ or from ${ }^{32} \mathrm{P}-8-\mathrm{N}_{3}$-cAMP incorporated into protein species by covalent bonds, were quantified by first correlating the radioactive bands with the Coomassie blue-stained bands by superimposing autoradiograms onto the dried, stained gel, and then cutting out the radioactive bands, hydrating with two droplets of $\mathrm{H}_{2} \mathrm{O}$ in Wheaton glass scintillation vials, followed by heating to about $60^{\circ} \mathrm{C}$ in the presence of additional droplets of 
$30 \% \mathrm{H}_{2} \mathrm{O}_{2}$ until the gel dissolved and dried. The radioactivity remaining in the vials was counted in a Beckman scintillation counter (model LS-350) in the presence of $2 \mathrm{ml}$ of $\mathrm{H}_{2} \mathrm{O}$ plus $12 \mathrm{ml}$ of Hydrofluor.

lodination of protein $A$. ${ }^{125}$-Protein $A$ was either obtained from New England Nuclear (70 to $100 \mu \mathrm{Ci} / \mu \mathrm{g}$ ) and used within 2 weeks, or iodinated according to the method of Richmond and Klee (1978). Protein A (2 mg) was dissolved in $0.5 \mathrm{ml}$ of $0.05 \mathrm{M}$ phosphate buffer $(\mathrm{pH} 7.0)$ with $3 \mu \mathrm{g}$ of lactoperoxidase and $1 \mathrm{mCi}$ of $\mathrm{Na}^{125}$. The reaction was initiated by adding $2.5 \mu \mathrm{l}$ of $\mathrm{H}_{2} \mathrm{O}_{2}$ (45 nmol). Seven minutes later, $\mathrm{H}_{2} \mathrm{O}_{2}$ was again added and the reaction was allowed to proceed for another $7 \mathrm{~min}$. The reaction mixture was immediately chromatographed on a Sephadex G-25-40 column ( $1 \times 10$ $\mathrm{cm}$ ), equilibrated with $0.05 \mathrm{M}$ Tris- $\mathrm{HCl}$ buffer $(\mathrm{pH} 7.5)$, and eluted with the same buffer. The $0.5-\mathrm{ml}$ elution aliquots were monitored for the presence of ${ }^{125} 1$-protein A with a Geiger counter and were confirmed by counting with a Packard Auto-Gamma scintillation spectrophotometer (model 5385). The peak activity was always in the fifth eluate at a radioactive concentration of 1 to $2 \mu \mathrm{Ci} / 5 \mu \mathrm{l}$. If $100 \%$ recovery is assumed, the specific activity of this fraction would be 50 to $10 \mu \mathrm{Ci} / \mathrm{mg}$.

Immunoblotting methods. Two hundred- to $500-\mu \mathrm{g}$ proteins of whole homogenates were separated by gel electrophoresis as described above and transblotted electrophoretically onto nitrocellulose paper $(0.45 \mu \mathrm{m}$ pore size) as described by Towbin et al. (1979), except that current at $200 \mathrm{~mA}$ for 12 to $24 \mathrm{hr}$ was applied, and the transfer buffer did not contain methanol. The procedures for binding primary antibody and peroxidase-conjugated antibody were according to the methods of Towbin et al., (1979), modified as follows. Following transblotting, nitrocellulose paper was rinsed with 10 $\mathrm{mm}$ Tris-130 mM saline several times over a 30 -min period and were preincubated with Tris-saline containing 5\% BSA at room temperature for $1 \mathrm{hr}$. Then, various amounts of the monoclonal antibody preparations were added to the buffer to give final dilutions of $1: 5000$ for $\mathrm{AP} 14,1: 50$ for $\mathrm{AP} 7$ and $\mathrm{AP}$ 13 , and 1:750 for the clone from A. Matus. The tray was swirled and then stored at $6^{\circ} \mathrm{C}$ for 3 days. The nitrocellulose paper was then rinsed three times with Tris-saline to remove the excess antibody, incubated with $5 \%$ BSA for 30 min at room temperature, and reacted with the second antibody, peroxidase-conjugated, affinity-purified rabbit anti-mouse IgG fraction, at a 1:3000 dilution. After $2 \mathrm{hr}$ of incubation at room temperature, the excess antibody was removed by rinsing with Tris-saline several times over a 30-min period, and then was placed in a substrate solution for peroxidase which contained $40 \mathrm{mg}$ of diaminobenzidine and $0.01 \% \mathrm{H}_{2} \mathrm{O}_{2}$ in a buffer consisting of $10 \mathrm{~mm}$ Tris- $\mathrm{HCl}$ plus $0.01 \mathrm{M}$ imidazole at $\mathrm{pH} 7.4$. After 0.5 to $8 \mathrm{~min}$, the reaction was stopped by immersing the nitrocellulose in deionized water. Immunoblots were dried on Whatman 3MM paper and photographed.

The procedure for visualizing antigens was done according to the radioactive method of Towbin et al. (1979). After binding with the primary antibody as described above, the nitrocellulose paper was incubated with rabbit antimouse antibody (1:25) for $2 \mathrm{hr}$ at room temperature. The excess antibody was removed by rinsing with Tris-saline several times during a 40 -min period, the paper was preincubated for 30 min with Tris-saline containing $5 \%$ BSA, and then to the buffer was added an aliquot of ${ }^{125} 1$-protein $A\left(2 \times 10^{6} \mathrm{cpm} /\right.$ $10 \mathrm{ml}$ ) while swirling the solution in the tray. After $1 \mathrm{hr}$ of incubation at room temperature, the excess protein A was removed by rinsing every $10 \mathrm{~min}$, first with Tris-saline, then twice with Tris-saline containing $0.1 \%$ Triton X-100, followed by one more rinse with Tris-saline. The nitrocellulose was dried under vacuum by sandwiching between Saran wrap and Whatman 3MM paper, and then was exposed to XRP-5 x-ray films with an intensifying screen for 1 week to obtain an autoradiogram.

One lane of the transblotted proteins was usually reserved for protein staining. This lane was cut away from those which were to be used for the immunoreaction, stained with amido black, destained, and matted onto Whatman 3MM paper, covered with Saran wrap, and dried under vacuum.

Quantification of the MAP 2 content in whole homogenates by the immunoblotting method. The procedure was that of Jahn et al., (1984), modified for the high lipid content in homogenates and for the application of primary and secondary antibodies. Protein $(400 \mu \mathrm{g})$ from whole homogenates of visual cortex area 17 was suspended in $100 \mu \mathrm{l}$ of $50 \mathrm{~mm}$ Tris/200 mm $\mathrm{NaCl} / 0.7 \%$ Triton $\mathrm{X}-100, \mathrm{pH} 7.40$, and blotted onto $1.5 \mathrm{~cm} \times 1.5 \mathrm{~cm}$ areas of nitrocellulose sheets $(0.45 \mu \mathrm{m}$ pore size) that had been prewashed with distilled water and then dried. After drying the homogenate spots with a gentle stream of air, the sheet was fixed with $25 \%$ isopropanol $/ 10 \%$ acetic acid $/ 65 \%$ water for $15 \mathrm{~min}$ and was rinsed several times with water, and then with the Tris-saline, followed by incubation at room temperature for at least $1 \mathrm{hr}$ with Tris-saline/0.1\% Triton X-100 containing $0.1 \%$ gelatin or $5 \%$ BSA (blocking buffer) to block nonspecific binding of antibodies. The sheet was then incubated for 3 to 4 days at $4^{\circ} \mathrm{C}$ with anti-MAP 2 antisera. For the antibody obtained from A. Matus, a dilution of 1:1,000 was used, whereas with the AP14 antibody from L. Binder, a 1:10,000 dilution was used. After rinsing five times for 5 min each with the Tris-saline to remove excess IgG, the sheet was reincubated at room temperature with the blocking buffer for $30 \mathrm{~min}$ and then reacted with rabbit anti-mouse antiserum (Jackson ImmunoResearch) diluted to 1:25 (unless specified otherwise) with the blocking buffer. After $2 \mathrm{hr}$ of incubation at room temperature, the sheet was rinsed five times for 5 min each with $0.1 \%$ Triton $X-100 /$ Tris-saline, then incubated at room temperature with the blocking buffer (using BSA) for 30 $\mathrm{min}$, followed by an incubation at room temperature for $1 \mathrm{hr}$ with ${ }^{125}$-protein A suspended at a concentration of $200,000 \mathrm{cpm} / \mathrm{ml}$ in the blocking buffer. At the end of the incubation period, the excess protein $A$ was rinsed off with five washes of $5 \mathrm{~min}$ each with $0.1 \%$ Triton X-100/Tris-saline, then with four washes of 20 min or longer with the blocking buffer (using BSA). The 1.5 $\mathrm{cm} \times 1.5 \mathrm{~cm}$ squares were separated and counted separately in a scintillation counter. Care was taken to use protein A that had been iodinated within 2 weeks. A standard curve relating tissue protein concentration, from 100 to $500 \mu \mathrm{g}$, to radioactivity was obtained for each immunoblotting assay, using adult visual cortex homogenate. This curve always had a linear coefficient greater than 0.90 . The radioactive protein $\mathrm{A}$ binding to an equivalent area of nitrocellulose sheet in the absence of tissue was always lower than the value extrapolated to zero tissue. The latter, higher, value was used as the nonspecific binding value and subtracted from every experimental value.

\section{Results}

Identification of some of the phosphoproteins. We began the study by first characterizing the cAMP-stimulated phosphorylation system in whole homogenates of the visual cortex of adult cats, since this system in the brain of this species had not been studied

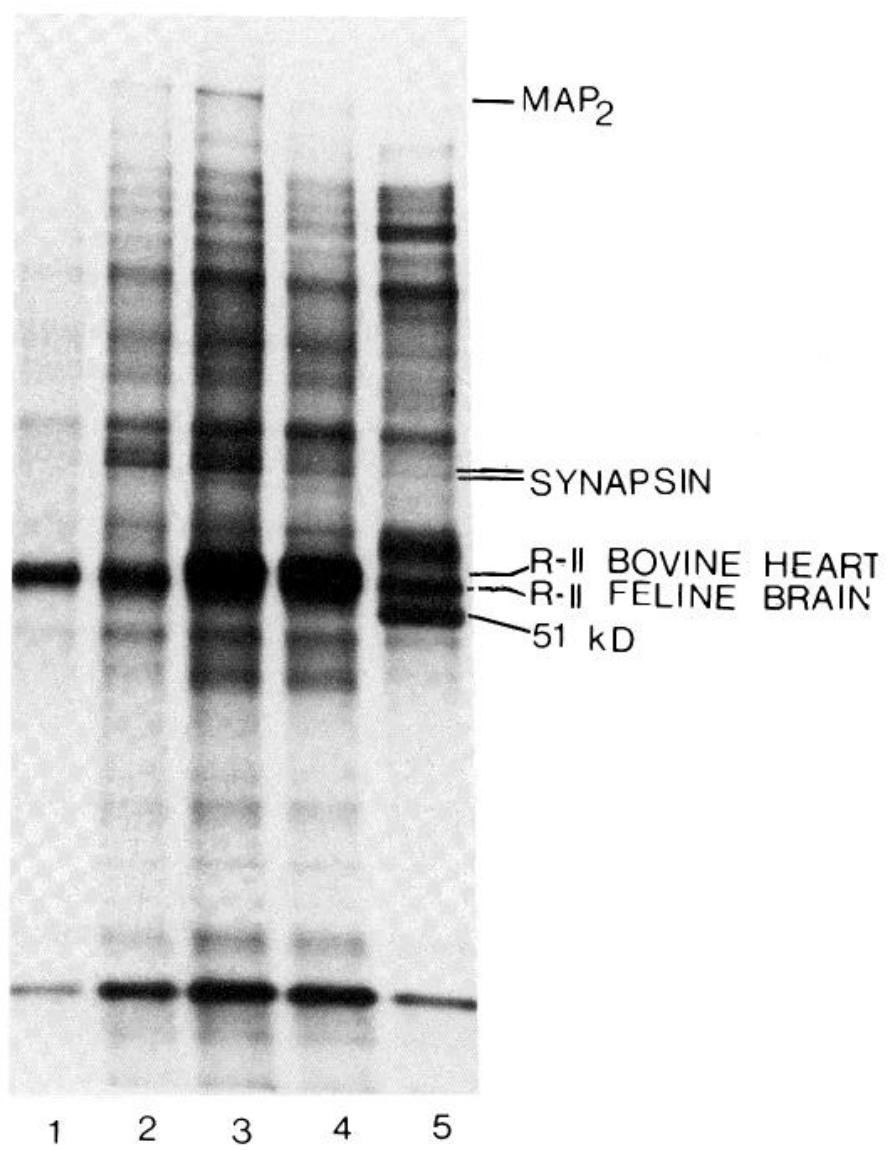

Figure 2. An autoradiogram showing the phosphoproteins in which phosphorylations are stimulated by cAMP or by $\mathrm{Ca}^{2+} /$ calmodulin. Phosphorylations were performed, SDS-gels were run, and autoradiograms were made as described under "Materials and Methods." Additions to the incubation buffer were: lane 1, nothing; lane 2, $10^{-5} \mathrm{M}$ cAMP; lane $3,10^{-5} \mathrm{M}$ cAMP and bovine CAMP-dependent protein kinase; lane 4 , the same kinase without cAMP; and lane $5,14 \mu \mathrm{g}$ of calmodulin with $0.5 \mathrm{mM} \mathrm{CaCl}_{2} .51 \mathrm{kD}$, major postsynaptic density protein (Carlin et al., 1980; Grab et al., 1981); R-II, regulatory subunit of type II cAMP-dependent protein kinase (cf. Fig. 3). 
Figure 3. An autoradiogram identifying the regulatory subunits of CAMP-dependent protein kinase. Samples of whole homogenates from the visual cortex of adult cats were photoaffinity labeled with varying concentrations of ${ }^{32} \mathrm{P}$-8-azidoCAMP followed by separation of proteins by SDS-PAGE (lanes 1 to 5 ) as described under "Materials and Methods." The concentrations were: lane $1,10^{-9} \mathrm{M}$; lane 2 , $10^{-8} \mathrm{M}$; lane $3,10^{-7} \mathrm{M}$; lane $4,10^{-6} \mathrm{M}$; lane $5,10^{-6} \mathrm{M}$ in the presence of $10^{-3} \mathrm{M}$ cAMP. The samples in lanes 6 to 8 were phosphorylated as described under "Materials and Methods." During the phosphorylation incubation, the following were added: lane 6, nothing; lane $7,10^{-6} \mathrm{M}$; lane $8,10^{-6} \mathrm{M}$ CAMP and bovine heart cAMP-dependent protein kinase. $R-\|^{*}$ is another form of the type II cAMP-dependent protein kinase (cf. "Results").

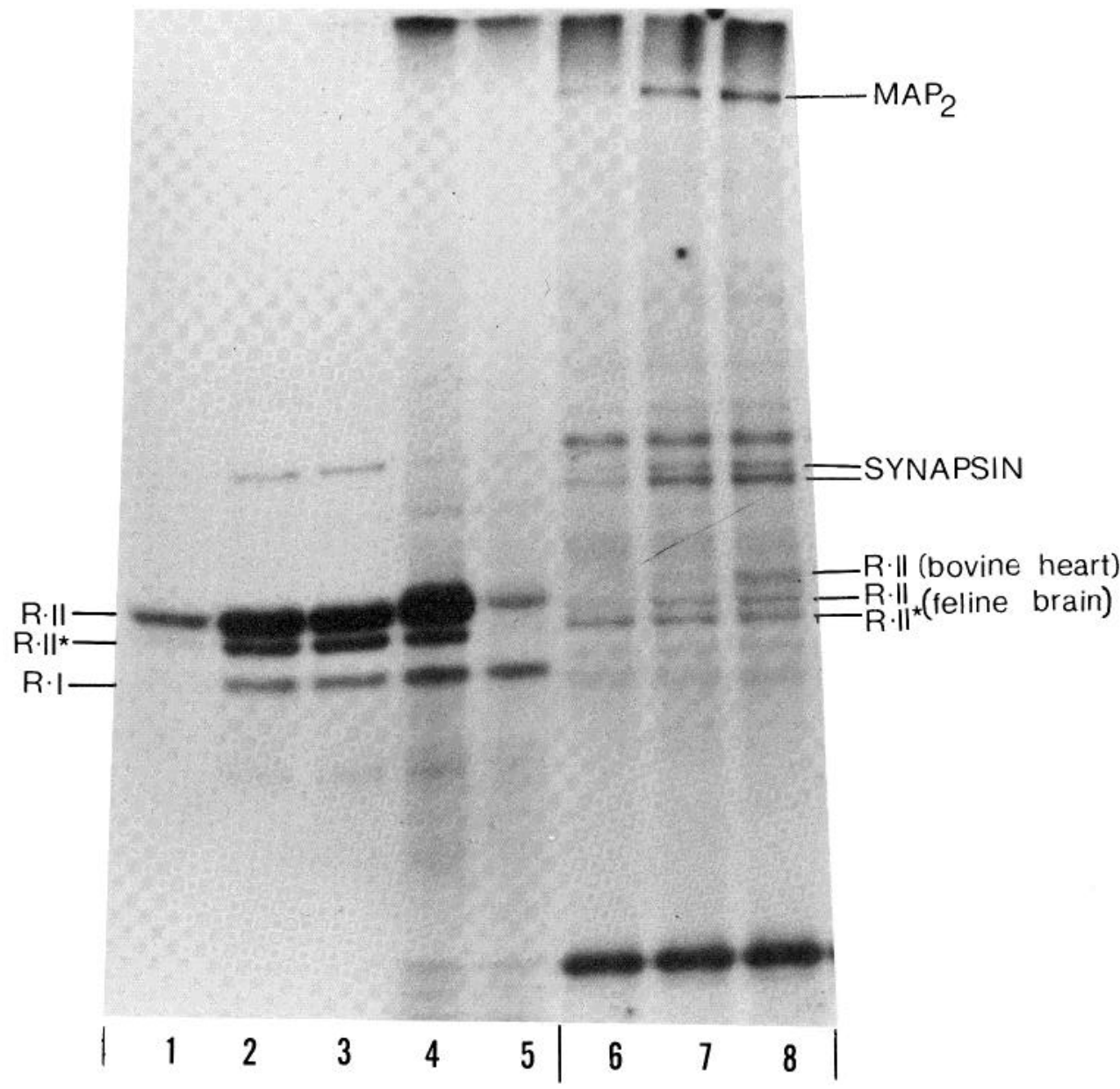

previously. In order to investigate the concentration of CAMP which would give optimal stimulation of CAMP-dependent phosphorylation in the presence of $10^{-5} \mathrm{M}$ ATP, cAMP concentrations ranging from $10^{-9}$ to $10^{-3}$ were added to the incubation system using whole homogenates of the visual cortices of adult cats in the presence and in the absence of exogenous bovine heart cAMP-dependent protein kinase. SDS gels were run and the dried Coomassie bluestained gels were then autoradiographed. By visual inspection of the autoradiograms, $10^{-7}$ to $10^{-6} \mathrm{M}$ was determined to be the concentration optimal for CAMP-stimulated phosphorylation of proteins, both with and without the exogenous kinase (data not shown). Concentrations of cAMP higher than $10^{-6} \mathrm{M}$ were found to be inhibitory, explanation unknown. Among the phosphoproteins prominently stimulated in a concentration-dependent manner were the doublet around 80 kilodaltons (kD) and a higher molecular weight protein with $M_{\mathrm{r}} \sim 300,000$.

We also wanted to know the state of phosphorylation of the proteins in whole homogenates. To examine this, we attempted to increase the number of dephosphorylated sites by preincubating homogenates for up to an hour at $30^{\circ} \mathrm{C}$ in the absence of ATP (Walaas and Greengard, 1984). This treatment was followed by the standard phosphorylation procedure in the presence of $10 \mu \mathrm{M}$ ATP and the bovine protein kinase. However, this preincubation step did not enhance the subsequent ${ }^{32} \mathrm{P}$-labeling of any phosphoprotein, as indicated by comparisons of the autoradiograms of the preincubated and non-preincubated samples (data not shown). The result indicated that the homogenize-freeze-thaw procedure left most phosphoproteins in a stable, mostly dephosphorylated, state. Once this was determined, we carried out all phosphorylations following a 60 sec preincubation with cAMP with or without exogenous kinase, in the absence of ATP, merely to equilibrate the temperature of the phosphorylation buffer to $30^{\circ} \mathrm{C}$.
For the identification of the species of phosphoproteins phosphorylated by CAMP-dependent protein kinase, the incubations of the whole homogenates were carried out under three conditions: (1) in the absence of any CAMP; (2) in the presence of $10^{-6} \mathrm{M}$ CAMP; and (3) in the presence of $10^{-6} \mathrm{M}$ CAMP and bovine CAMP-dependent protein kinase. By comparing condition 1 with condition 2, we could identify those proteins in which phosphorylation was stimulated by CAMP. With the addition of the exogenous kinase, it was found that, in most cases, there was a further increase in the phosphorylation of every phosphoprotein, indicating that at the ATP concentration of $10 \mu \mathrm{M}$, the phosphorylation system in the homogenate was limited by the activity of the endogenous kinase. Thus, we used condition 3 . which allowed for maximal phosphorylation of substrates, to estimate the concentration of the protein species and the frequency of unphosphorylated sites on each molecule.

Some of the identifiable proteins in which phosphorylations were increased by the additions of CAMP and $\mathrm{Ca}^{2+} /$ calmodulin are indicated in Figure 2. The doublet band marked synapsin was identified by its phosphorylation being increased by cAMP (Fig. 2, lanes 1 to 3 ; also cf. lanes 6 to 8 of Fig. 3) and by its identical movement on gels to the protein doublet identified as synapsin in a postsynaptic both the visual cortex whole homogenate and postsynaptic density preparation, its phosphorylation is clearly stimulated by $1 \mu \mathrm{M}$ cAMP and not by cGMP, as well as by the addition of $0.5 \mathrm{mM} \mathrm{CaCl}$ with $14 \mu \mathrm{g}$ of calmodulin (Fig. 2, lane 5). These characteristics led us to conclude that the doublet in the whole homogenate preparation is probably the $80 / 86-k D$ synapsin I (formerly named protein I, Ueda and Greengard, 1977). The protein band marked $51 \mathrm{kD}$ is the major postsynaptic density protein in which phosphorylation is increased by $\mathrm{Ca}^{2+} /$ calmodulin but not by cAMP (Carlin et al., 1980; Grab et density fraction (Ueda et al., 1979), as seen in Figures 5 and 6 . In 
A
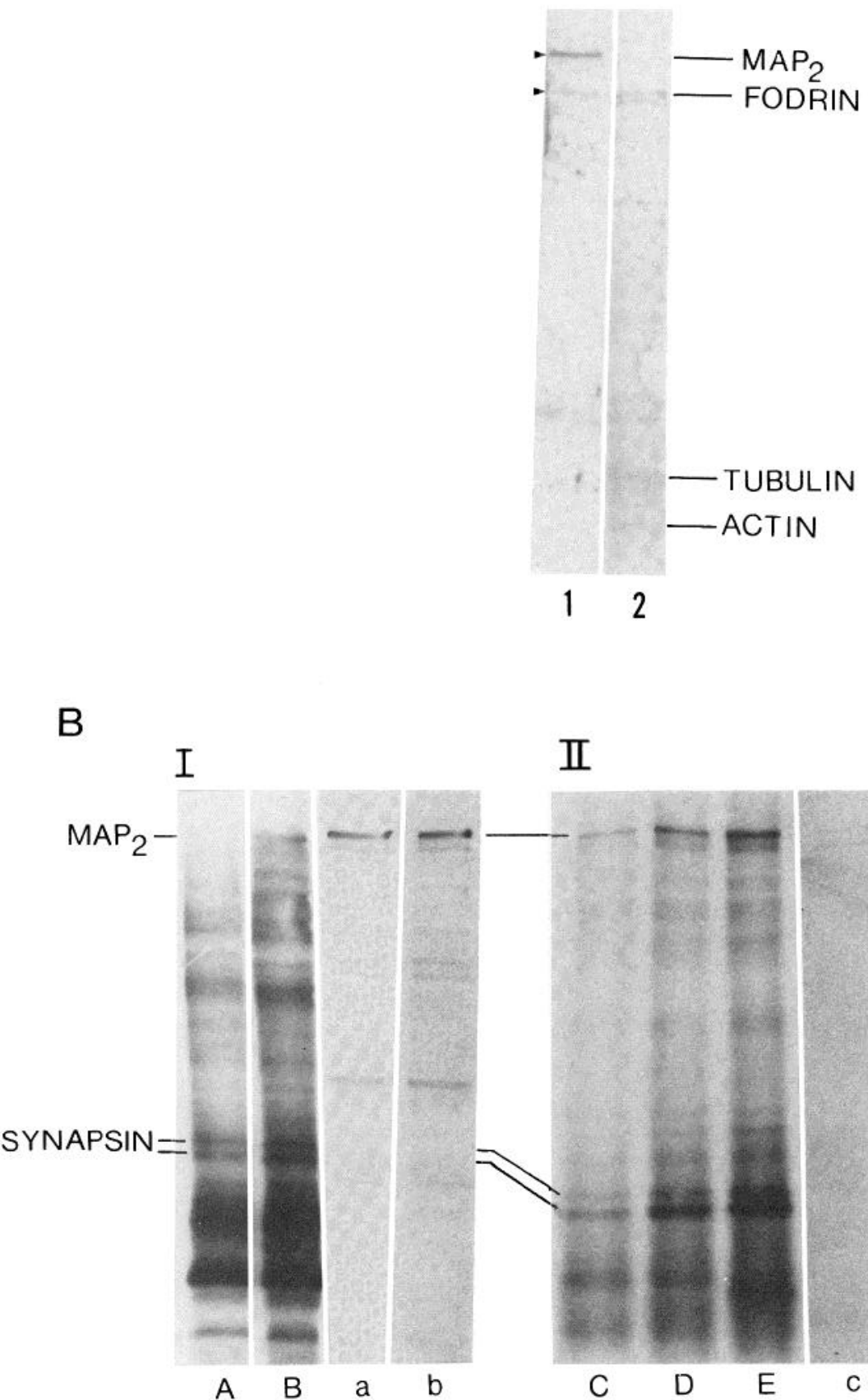

II

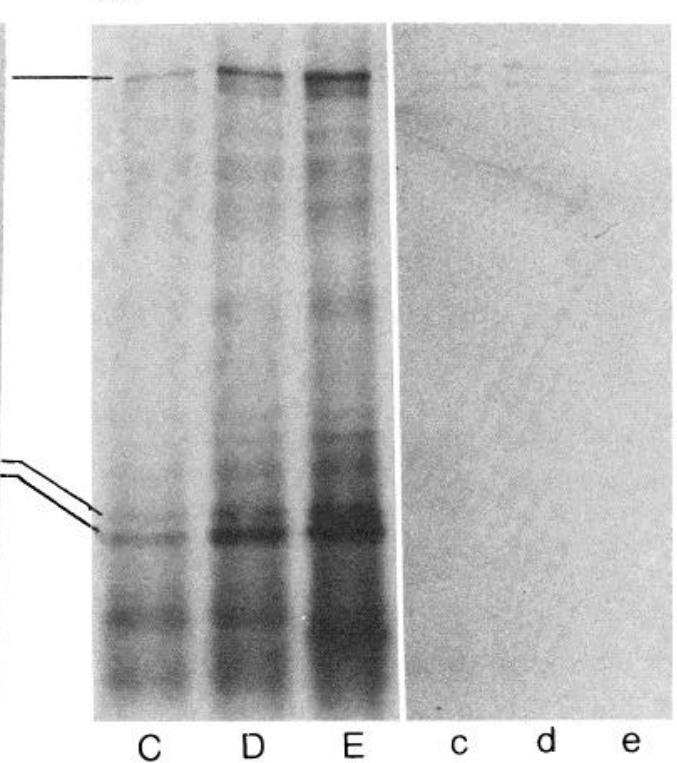

Figure 4. Identification of MAP $2 \mathrm{immu}$ nologically and by cAMP-dependent phosphorylation. $A$, A whole homogenate sample from an adult visual cortex was electrophoresed by SDS.PAGE and, as described under "Materials and Methods," transblotted onto nitrocellulose paper, then reacted with the anti-MAP 2 antiserum (obtained from A. Matus) and anti-fodrin antiserum, followed by procedures to visualize the antigens us ing ${ }^{125}$-protein A. Protein A was radioiodinated and used as described under "Materials and Methods." Lane 1: Antibody-reacted transblot; lane 2: amido black-stained transblot. $B$, Visual cortex homogenates of a 5-month dark-reared cat were phosphorylated as described under "Materials and Methods" with the following additions: lanes $A$ and $C$, nothing; lanes $B$ and $D, 10^{-6} \mathrm{M}$ cAMP; lane $E, 10^{-6} \mathrm{M}$ cAMP plus bovine cAMP-dependent protein kinase. Following phosphorylation, the samples were run on SDS-polyacrylamide gels and were Western-blotted onto nitrocellulose paper. MAP 2 bands were identified by reacting the paper with monoclonal antibodies raised against MAP 2, followed by a binding with peroxidase-conjugated rabbit anti-mouse antibody; then they were exposed to x-ray films to obtain autoradiograms of the phosphorylated proteins from the same blot ("Materials and Methods"). $A$ to $E$ are autoradiograms of the transblot, and a to e show the peroxidase products of the immunolog. ical reactions on the transblot. In experiment $I$, lanes $a$ and $b$ show the reaction products using a monoclonal antibody obtained from A. Matus; in experiment II, lanes $c$ to $e$ show the reaction products using the antibody (clone AP 14) obtained from L. Binder. al., 1981). The identifications of MAP 2 and R-ll will be discussed below.

Another phosphoprotein in which phosphorylation is stimulated by cAMP migrates more slowly than does the $51-\mathrm{kD}$ protein (Fig. 2). The cAMP-stimulated phosphorylation of this protein is shown in Figure 3 (lanes 6 to 8 ). Its binding of cAMP, using a photoaffinity label, is also shown in Figure 3 (lanes 1 to 4 ); the specificity of the binding is indicated by the decrease of radioactive binding in the presence of a high concentration of unlabeled cAMP (Fig. 3, lane 5). These characteristics, together with its gel mobility, indicate it to be the regulatory subunit of the type II cAMP-dependent protein kinase (Hofmann et al., 1975; Walter et al., 1978; Lohmann et al., 1980). The $R-I^{\star}$ band in lanes 1 to 4 of Figure 3 is probably another form of this protein (Rangel-Aldao et al., 1979; Lohmann et al., 1980), whereas R-I is the regulatory subunit of the type I cAMP-dependent protein kinase which is not phosphorylated (Hofmann et al., 1977; Rangel-Aldao et al., 1979; Lohmann et al., 1980). When the exogenous bovine heart kinase is added, its regulatory subunit is also phosphorylated, but it migrates more slowly than does the endogenous feline brain kinase on the SDS gels (Fig. 2, lanes 3 and 4; Fig. 3, lane 8), as has been previously found (Lohmann et al., 1980; Sarkar et al., 1984).

The third identifiable phosphoprotein was a protein of high molecular weight migrating above a doublet in the $230-\mathrm{kD}$ region. The $230 / 235-\mathrm{kD}$ doublet was identified as fodrin by its co-migration with the fodrin doublet in postsynaptic densities (cf. Fig. 5) (Carlin et al., 1983) and by the antigenicity of the upper band (Fig. 4A, lane 1) to the anti- $\alpha$-fodrin antibody raised and characterized by this laboratory (Carlin et al., 1983). The molecular weight of the phosphoprotein of higher molecular weight was estimated from its rate of migration 


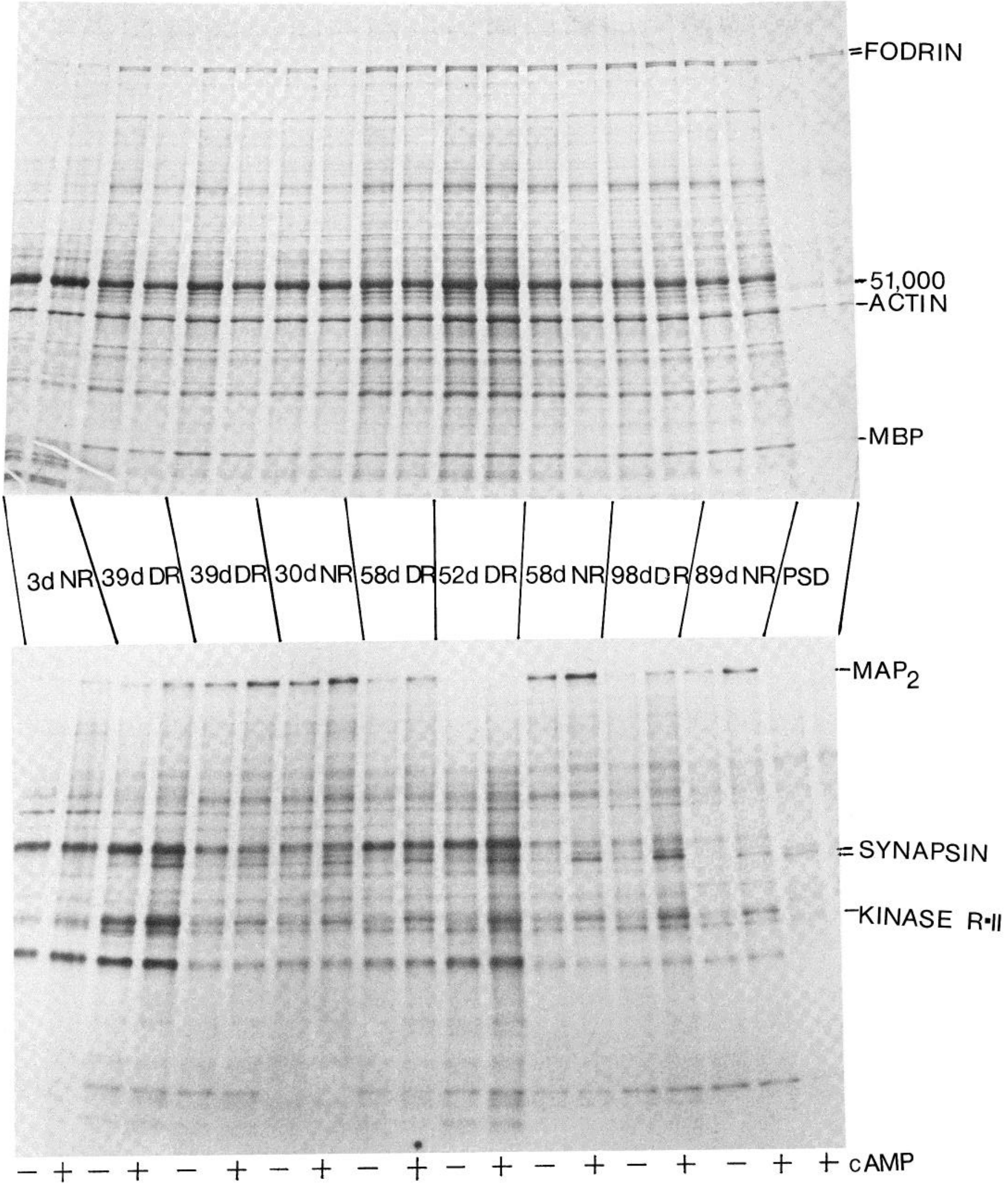

Figure 5. A Coomassie-stained (upper panel) SDS-gel and an autoradiogram (lower panel) of phosphorylations in visual cortex homogenates of cats of different ages, reared normally or in the dark. Phosphorylations were performed, the gel was run, and the autoradiogram was made as described under "Materials and Methods." Protein kinase was added to every sample, and $1.0 \mu \mathrm{M}$ CAMP was added to the lanes indicated. 51,000, major PSD protein; MBP, myelin basic protein; $P S D$, postsynaptic density which was run as a protein(s) identification marker (Cohen et al., 1977); NR, normally reared; $D R$, dark reared; $d$, days. 39d $D R$ was taken from an area spanning area 18 as well as area 17. 
TABLE 1

The relative phosphorylation of MAP 2 in visual cortex homogenates from normally reared and dark-reared cats of different ages

Whole homogenates containing $100 \mu \mathrm{g}$ of protein were phosphorylated with $10 \mu \mathrm{M}\left[\gamma^{32} \mathrm{P}\right] A T P(5 \mu \mathrm{Ci} /$ assay) in the presence of $1 \mu \mathrm{M}$ CAMP and bovine heart CAMP-dependent protein kinase, run on SDS gels, stained, and dried. MAP 2, identified as the radioactive bands in the 300-kD-region in the autoradiogram, were cut out from the gel, dissolved, and counted for ${ }^{32} \mathrm{P}$ radioactivity as described under "Materials and Methods." The degree of de novo phosphorylation of MAP 2 is expressed as counts per minute (CPM). The ratio values were obtained by averaging all of the normally reared or dark-reared values within the 1-, 2-, or 3-month age brackets. The autoradiograms and the Coomassie blue-stained gels from which the cpm values were obtained are shown in Figure 5.

\begin{tabular}{lll}
\hline \multicolumn{1}{c}{ Tissue Source } & \multicolumn{1}{c}{ CPM } & NR/DR Ratio \\
\hline 3-d NR & \\
1-month-old cats & 276 & 1.13 \\
30-d NR & & \\
39-d DR & 524 & \\
39-d DR & 443 & 2.0 \\
2-month-old cats & 482 & \\
58-d NR & & \\
52-d DR & 547 & \\
58-d DR & $169,153^{c}$ & 1.20 \\
3-month-old cats & $354,381^{c}$ & \\
89-d NR & & \\
97-d NR & 361 & \\
98-d DR & 286 & \\
\hline
\end{tabular}

${ }^{a} \mathrm{~d}$, days; NR, normally reared; DR, dark reared.

${ }^{b}$ Areas 17 plus 18.

${ }^{c}$ Counts per minute obtained from another experiment.

above the $230 / 235-\mathrm{kD}$ fodrin doublet to be about 300,000 . The phosphorylation of this protein was strongly stimulated by the addition of $10^{-6} \mathrm{M}$ CAMP (Fig. 3, lanes 7 and 8 ; Fig. $4 B$, lanes $A$ to $E$ ) but not by $\mathrm{Ca}^{2+}$ /calmodulin (Fig. 2, lane 5). Again, the increased phosphorylation of synapsin by the addition of cAMP was used as an indication that the phosphorylation system was operating. The size and phosphorylation properties of the $300-\mathrm{kD}$ protein match well with those of a cytoskeletal protein, MAP 2 (Shigekawa and Olsen, 1975; Sloboda et al., 1975; Rappaport et al., 1976; Lohmann et al., 1980; Vallee et al., 1981; Theurkauf and Vallee, 1982). These observations led us to determine whether this phosphoprotein would react with anti-MAP 2 antibodies. In Figure 4A, lane 1, can be seen the autoradiographic band above that of anti- $\alpha$-fodrin, obtained when the SDS gel of an adult visual cortex was transblotted onto nitrocellulose paper and reacted with an anti-MAP 2 antiserum and radioactive protein $A$; this band was seen to have migrated to the 300 $\mathrm{kD}$ region. To verify this identification further, we phosphorylated whole visual cortex homogenates with and without cAMP, separated the proteins on SDS-gels, transferred them onto nitroccllulosc papers by the procedure described under "Materials and Methods," and then reacted them with monoclonal antibodies from four clones obtained from two different laboratories. Then the antibody-reactive proteins were visualized by the peroxidase reaction. In Figure $4 B$, lanes $a$ and $b$, the rcactive proteins against the clone from A. Matus can be seen, whereas in lanes $c, d$, and $e$, the proteins reactive against clone 14 from $\mathrm{L}$. Binder can be seen. The most reactive band superimposed perfectly upon the radioactive band in the 300 $\mathrm{kD}$ region which was visualized in the autoradiogram obtained from the same nitrocellulose blots (Fig. 4B, lanes $A$ to $E$ ). Thus, we have determined the protein of high molecular weight to be MAP 2 by three criteria: (1) its mobility on SDS-gels; (2) its phosphorylation which is stimulated by CAMP; and (3) its reaction with four monoclonal antibodies against MAP 2.

Ontogenetic changes of the identified visual cortex phosphoproteins. The critical period for the formation of the neural circuitry underlying ocular dominance spans from about the fourth week through the fourth month in cats. We examined the phosphorylation of the proteins identified above throughout this period, as well as during the period before and after the critical period. From visual inspections of the autoradiograms obtained after phosphorylation. (Fig. 5, lower panel), synapsin, a prominent phosphoprotein reported to be enriched at synapses, appears to be at the adult level at 1 month of age. However, in 3-day-old brain tissue, its level, as noted by a lack of phosphorylation, is markedly less (Fig. 5, lower panel). The content of the CAMP-dependent protein kinase was estimated by observing the bands of autophosphorylation (Fig. 5, lower panel) and the binding of ${ }^{32} \mathrm{P} \cdot 8-\mathrm{N}_{3}$-CAMP in autoradiograms (data not shown). By these methods, it was estimated that the R-Il content is higher at 1 month of age than in the 2-and 3-month tissues or in the adult tissue. The autophosphorylation band is clearly visible in the 3-day tissue as well (Fig. 5, lower panel). As for MAP 2, by examining the autoradiograms (Fig. 5, lower panel) and by counting the ${ }^{32} \mathrm{P}$ incorporated into the protein bands with a scintillation counter (Table I), it was found to be present already in the 3-day-old kitten's visual cortex. The phosphorylation of MAP 2 increased postnatally in the first month, was higher in the second month after birth, which is well within the critical period, and declined slightly in the third month.

The effect of dark-rearing through the critical period upon phosphorylation of the visual cortex phosphoproteins. In order to study the effect of light deprivation upon the ontogenetic development of the cAMP-dependent phosphorylation system, eight litters, totaling 22 kittens, were reared in complete darkness with the mother for 39 days, 40 days, 52 days, 58 days, 59 days, 90 days, 98 days, and 5 months. Their tissues were compared with those of normally reared kittens of ages 30 days, 58 days, 97 days, and adults. Routinely, after autoradiograms were generated from the dried gels, the bands containing the phosphoproteins R-ll, synapsin, and MAP 2 were processed for counting in a scintillation counter as described under "Methods and Materials." Comparisons among the litters were made in two ways: one way was to normalize separately the counts for MAP 2 and synapsin to a reference animal (cf. Table I), and the other method was to normalize within the littermates the MAP 2 counts to synapsin counts, since the synapsin counts did not appreciably differ among littermates reared under various conditions (cf. Tables II to V).

Figure 5 is a representative autoradiogram showing a direct quantitative and qualitative comparison of the phosphoproteins from dark-reared versus normally reared cats at approximately 1,2 , and 3 months of age. Equal amounts of protein $(100 \mu \mathrm{g})$ were used in each case and, as can be seen (Fig. 5, upper panel), no differences were observed in the protein banding pattern and little difference was seen in the protein concentrations relative to each other. Both the phosphorylations of the regulatory subunit of the CAMP-dependent protein kinase and of synapsin were somewhat higher under dark-rearing conditions, whereas the phosphorylation of MAP 2 was dramatically decreased after about 2 months of dark rearing (Fig. 5 , lower panel). When this comparison was made quantitative by counting the bands in a scintillation counter, the ratios of ${ }^{32} \mathrm{P}$ incorporation into MAP 2 of normally reared to the dark-reared animals were 1.13 for the 1-month group, 2.07 for the 2-month group (average of two values, 3.40 and 1.49, for the animals, 52-d-DR and 58-d-DR, respectively), and 1.20 for the 3 -month group (Table I). The ratio values for the 1 -month and 3 -month animals are not considered significant. The reason for the different degree of decrease in MAP 2 phosphorylations between the two 2-month darkreared animals is unclear, but as will be discussed below, their littermates that were exposed to light exhibited values very similar to one another, indicating that interlitter differences within agematched animals are smaller than the differences seen here.

The effect of exposure to light following dark rearing on protein phosphorylation in the visual cortex. The effect of light exposure after dark rearing on phosphorylation in the visual cortex was first 


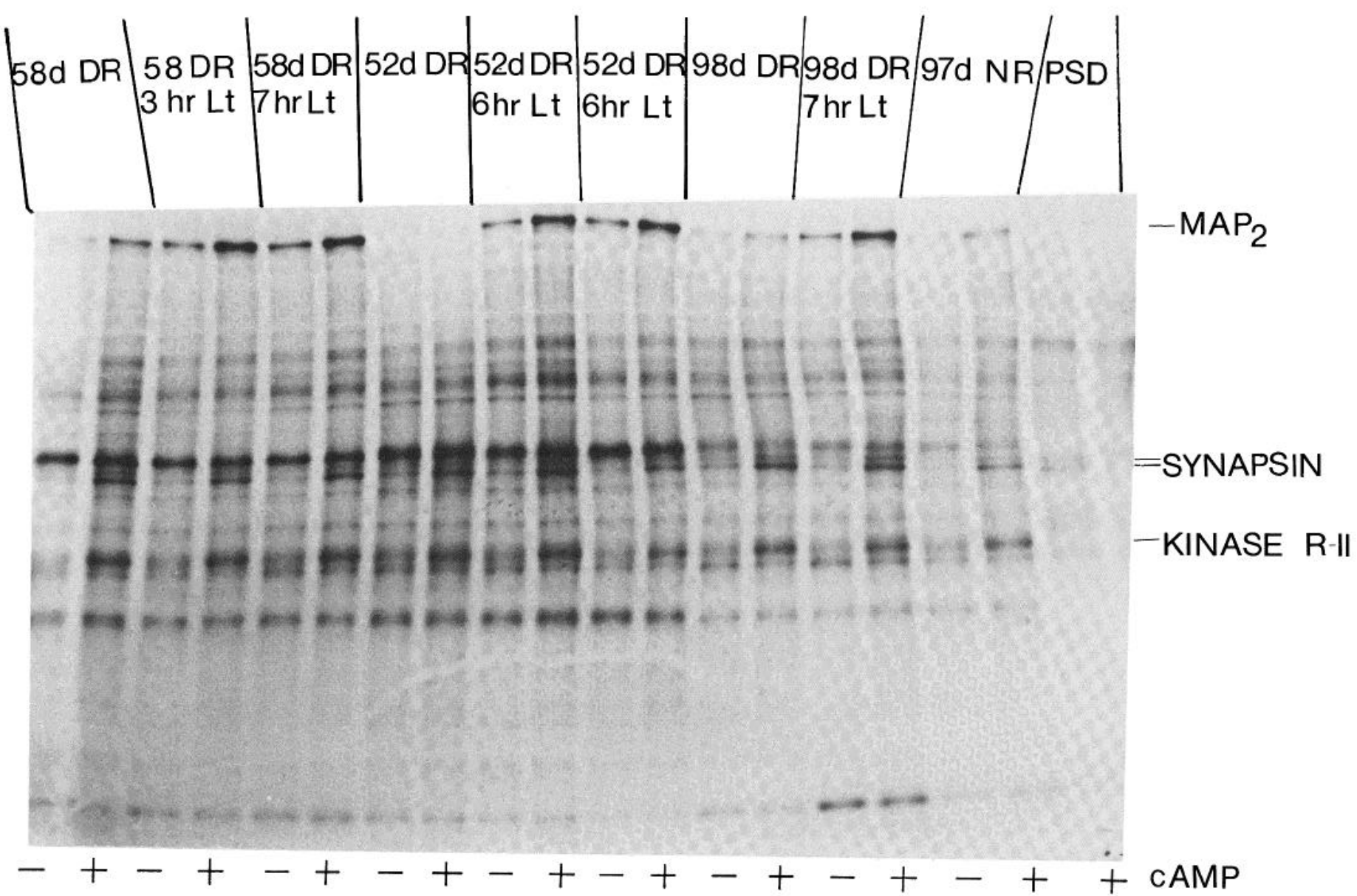

Figure 6. The effect of exposure to light following dark rearing on phosphorylation of MAP 2 in the visual cortex. Homogenates used for phosphorylation were obtained from visual cortices of littermates that were either dark-reared $(D R)$ or dark-reared followed by exposures to light $(L t)$ as indicated. Four litters were used: 52d DR, 58d DR, 98d DR, and 97d NR. The two sets labeled 52d DR $6 \mathrm{hr} L \mathrm{t}$ were from two different animals of the same litter. To all samples were added bovine heart cAMP-dependent protein kinase and CAMP $(1.0 \mu \mathrm{M})$ as indicated. Gels were run and autoradiograms were made as described under "Materials and Methods."

TABLE ॥

The effect of light exposure following dark rearing on the relative phosphorylation of MAP 2 and synapsin in the visual cortex homogenates of cats of different ages

Values for counts per minute (cpm) were obtained as described in Table I. Synapsin was identified by its mobility on the gel, using the synapsin doublet in the $80-\mathrm{kD}$ region in preparations of postsynaptic densities as the marker. The MAP 2 and synpasin values were normalized separately by setting the dark-reared values for each age bracket equal to 1.00 . The MAP $2 /$ synapsin ratios were obtained from these normalized values. The autoradiogram from which the cpm values were obtained can be seen in Figure 6.

\begin{tabular}{|c|c|c|c|}
\hline Tissue Source & MAP 2 & Synapsin & MAP 2/Synapsin \\
\hline $52-d^{D R^{a}}$ & $1.00(153 \mathrm{cpm})$ & $1.00(855 \mathrm{cpm})$ & 1.00 \\
\hline 52-d DR + 6-hr Lt & 3.48 & 1.09 & 3.19 \\
\hline $52 \cdot d \mathrm{DR}+6-\mathrm{hr} \mathrm{Lt}$ & 3.38 & 0.89 & 3.80 \\
\hline 58-d NR & 3.58 & & \\
\hline 58-d DR & 1.00 (381 cpm) & 1.00 (837 cpm) & 1.00 \\
\hline 58-d DR + 3-hr Lt & 1.36 & 0.74 & 1.84 \\
\hline 58-d DR + 7-hr Lt & 1.43 & 0.81 & 1.76 \\
\hline 58-d NR & 1.44 & & \\
\hline 98-d DR & 1.00 (257 cpm) & 1.00 (696 cpm) & 1.00 \\
\hline 98-d DR + 7-hr Lt & 2.18 & 1.07 & 2.04 \\
\hline 97-d NR & 1.11 & 0.82 & 1.35 \\
\hline
\end{tabular}

\footnotetext{
a d, day; DR, dark reared; NR, normally reared; Lt, exposure to light.
}

tested on 3-month-old kittens which had been reared in the dark since birth. It was found that a 3 -month or a $1 \frac{1}{2}-$-month subsequent light exposure of these animals enhanced the phosphorylation of MAP 2 and not of synapsin as compared to the 3 -month dark control (data not shown).

To test whether shorter periods of light exposure were sufficient to generate this change, in other litters some of the dark-reared kittens were exposed to a few hours of light before sacrifice. The phosphorylation of proteins was then compared within the litter as well as with other litters. The phosphorylation of synapsin and R-\|l, which was somewhat increased by the dark-rearing conditions, was not altered by the subsequent light exposure (Fig. 6). Thus, counts in synapsin were used as a reference standard for comparisons of MAP 2 phosphorylation (Table II) in order to correct for variabilities accountable by the differences of protein content among the assays. In contrast to synapsin, the cAMP-stimulatable phosphorylation of MAP 2 was dramatically enhanced by 3 to $7 \mathrm{hr}$ of light exposure following dark rearing in every litter examined. Figure 6 shows a direct qualitative comparison within litters of the phosphorylation pattern following dark rearing with and without the brief exposure to light just before sacrifice. When compared with the dark-reared cat, labeled 52d $D R$, its two littermates (52d DR, $6 \mathrm{hr} L t$ ) exhibited a $248 \%$ and $238 \%$ enhancement of phosphorylation under the incubation condition containing CAMP and exogenous bovine kinase (Table II). Two other assays using the same tissues gave $155 \%$ and $71 \%$ increases (data not shown). A litter dark-reared for 58 days exhibited $36 \%$ and $43 \%$ enhancement in phosphorylation of MAP 2 


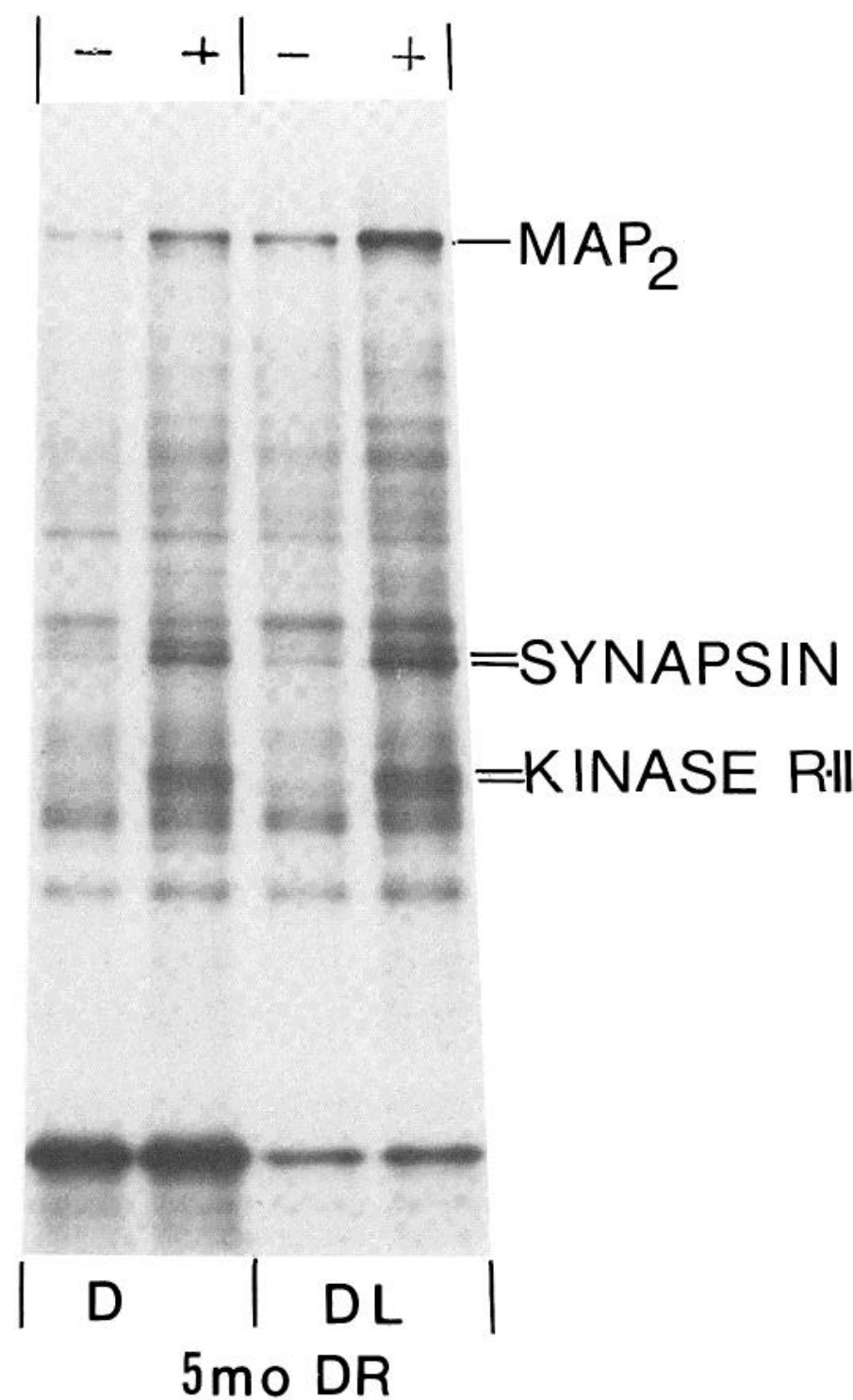

Figure 7. The effect of exposure to light following 5 months of dark rearing on phosphorylation of MAP 2 in the visual cortex. Homogenates used for phosphorylation were obtained from a kitten which was dark-reared from birth for 5 months $(D)$, or from its littermate which was dark-reared from birth for 5 months and then exposed to light for $3 \mathrm{hr}(D L)$. Phosphorylations were performed in the presence $(+)$ or absence $(-)$ of $1.0 \mu \mathrm{M}$ CAMP and bovine heart CAMP-dependent protein kinase, as described under "Materials and Methods" SDS-gel electrophoresis was performed, and autoradiograms, prepared as described.

when two of the animals were put into the light (Table II). When these values were normalized to synapsin phosphorylation, the effect of light on MAP 2 phosphorylation was in most cases even greater (Table II, column 4). Thus, the effect of dark rearing for 52 and 58 days was to decrease the in vitro ability to phosphorylate which then returned to levels close to that of age-matched normally reared brains upon exposures of animals to a few hours of light. Another litter dark-reared for 59 days showed, in three assays, $32 \%, 33 \%$, and $43 \%$ enhancement of MAP 2, normalized for the synapsin content, when some of the animals were put into the light for $5 \mathrm{hr}$ (data not shown). Similarly, following 98 days of dark rearing, there was a $118 \%$ enhancement in the phosphorylation of MAP 2 following $7 \mathrm{hr}$ of exposure to light (Table II). Analogous experiments were done using a litter in which the critical period was postponed beyond its usual chronological age, by keeping an animal in the dark for 5 months after birth. Some animals of these litters were then exposed

\section{AUDITORY} CORTEX

VISUAL CORTEX

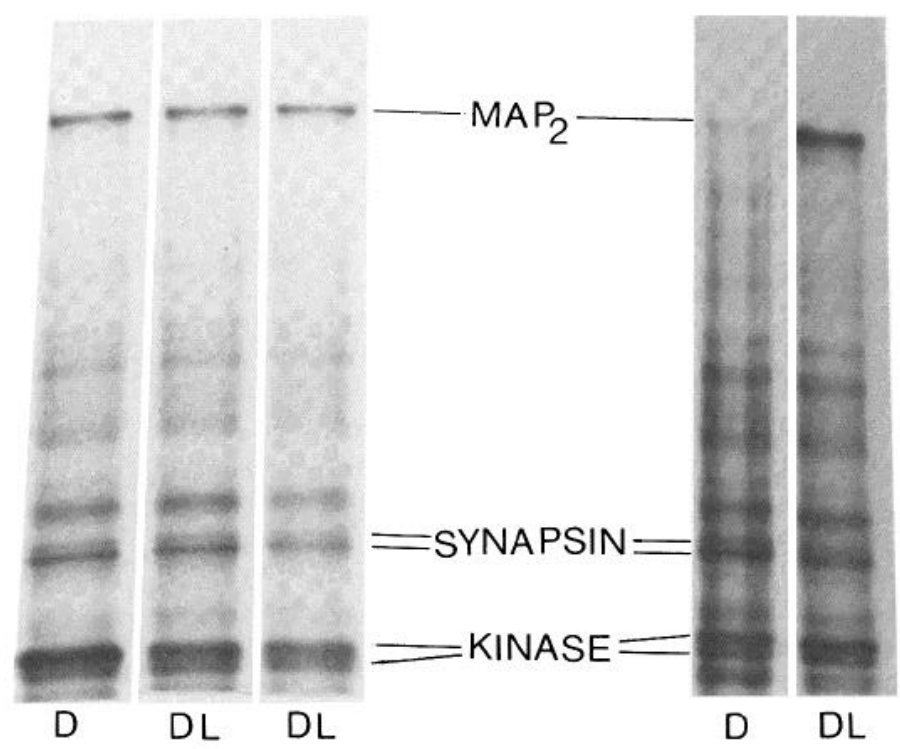

Figure 8. A comparison of the effect of exposure to light following dark rearing on phosphorylation of MAP 2 in the auditory cortex and visual cortex. All samples were whole homogenates from the 52-day dark-reared litter. Whole homogenates containing $50 \mu \mathrm{g}$ of protein were suspended in buffer and phosphorylated in the presence of $1.0 \mu \mathrm{M}$ CAMP and exogenous bovine CAMP-dependent protein kinase as given under "Materials and Methods." Gels were run and autoradiograms were made as described under "Materials and Methods." $D$, dark-reared for 52 days; $D L$, dark-reared for 52 days, followed by $6 \mathrm{hr}$ light. The $D L$ of auditory cortex lanes are from two different animals; the $D$ and $D L$ lanes of visual cortex are from the same animals as the $D$ and one of the $D L$ lanes of auditory cortex.

to light, and, whether the comparisons were made in the absence or in the presence of CAMP, exposures to light enhanced the degree of phosphorylation of MAP 2 in the visual cortex. Figure 7 indicates that, although there was no increase, as compared to the darkreared control $(D)$, of the phosphorylations of synapsin and of the kinase R-II regulatory subunit in the visual cortex of the dark-reared kitten which was then exposed to light for $3 \mathrm{hr}(D L)$, the phosphorylation of MAP 2 was visibly increased in the visual cortex of the DL kitten as compared to the D kitten.

In the 2-month animals, the phosphorylation of MAP 2 was always lower in the visual cortex of dark-reared animals compared to the normal animals, whereas in the 3-month animals, the phosphorylation of MAP 2 was the same in both situations (Table II). However, in both cases, exposure of the dark-reared animals to light resulted in an increase of MAP 2 phosphorylation: in the 2-month animal, this increased phosphorylation brought the level of phosphorylation up to that of the normally reared animal, whereas in the 3-month animal, this increased phosphorylation resulted in a level higher than that of the normally reared animal (Table II).

The effect of exposure to light following dark rearing on protein phosphorylation in the auditory cortex and in the LGN. The environment for the developing kittens was designed to introduce a purely visual stimulus following complete visual deprivation. Having observed that the exposure to light correlated with an enhancement in the phosphorylation of MAP 2 in the visual cortex, we wanted to observe whether increased MAP 2 phosphorylation following light exposure occurred in other cortical areas. Thus, we studied the phosphoproteins from the homogenates of the primary auditory area of the litters dark-reared for 52 days, 59 days, and 5 months, each of which exhibited pronounced enhancement in phosphorylation of MAP 2 in the primary visual cortex (cf. Fig. 6 and Table II). In none of the three litters did we see any enhancement of cAMP-stimulatable 
TABLE III

A comparison between visual cortex and auditory cortex of the effect of light exposure following dark rearing on the relative phosphorylation of MAP 2, synapsin, and the regulatory subunit of the type II cAMP-dependent protein kinase (R-II)

Values for cpm were obtained as described in Table I, except that $50 \mu \mathrm{g}$ instead of $100 \mu \mathrm{g}$ of protein were used per reaction and, in the case of the R-\| values, the incubation medium did not contain exogenous bovine heart kinase but did contain $1 \mu \mathrm{M}$ CAMP. The criteria for the identification of MAP 2 , synapsin, and R-\|l are described under "Results." The normalized values were obtained as desribed in Table II. The autoradiogram from which the values were obtained can be seen in Figure 8 except for those of the 59-day litter.

\begin{tabular}{lllll}
\hline \multicolumn{1}{c}{ Tissue Source } & \multicolumn{1}{c}{ MAP 2 } & \multicolumn{1}{c}{ Synapsin } & \multicolumn{1}{c}{ R-\|l } \\
\hline V-52-d DR & $1.00(838 \mathrm{cpm})$ & $1.00(3160 \mathrm{cpm})$ & $1.00(4485 \mathrm{cpm})$ & 1.00 \\
V-52-d DR + 6-hr Lt & 2.55 & 0.92 & 0.88 & 2.78 \\
A-52-d DR & $1.00(1971 \mathrm{cpm})$ & $1.00(2993 \mathrm{cpm})$ & $1.00(3094 \mathrm{cpm})$ & 1.00 \\
A-52-d DR + 6-hr Lt & 0.82 & 0.78 & 1.39 & 1.04 \\
A-52-d DR + 6-hr Lt & 1.50 & 1.40 & 2.55 & 1.07 \\
A-59-d DR & $1.00(697 \mathrm{cpm})$ & $1.00(1144 \mathrm{cpm})$ & $1.00(1289 \mathrm{cpm})$ & 1.00 \\
A-59-d DR + 6-hr Lt & 0.99 & 1.03 & 0.63 & 0.97 \\
\hline
\end{tabular}

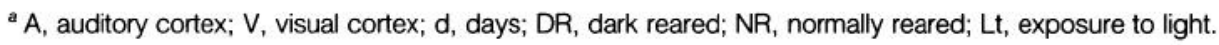

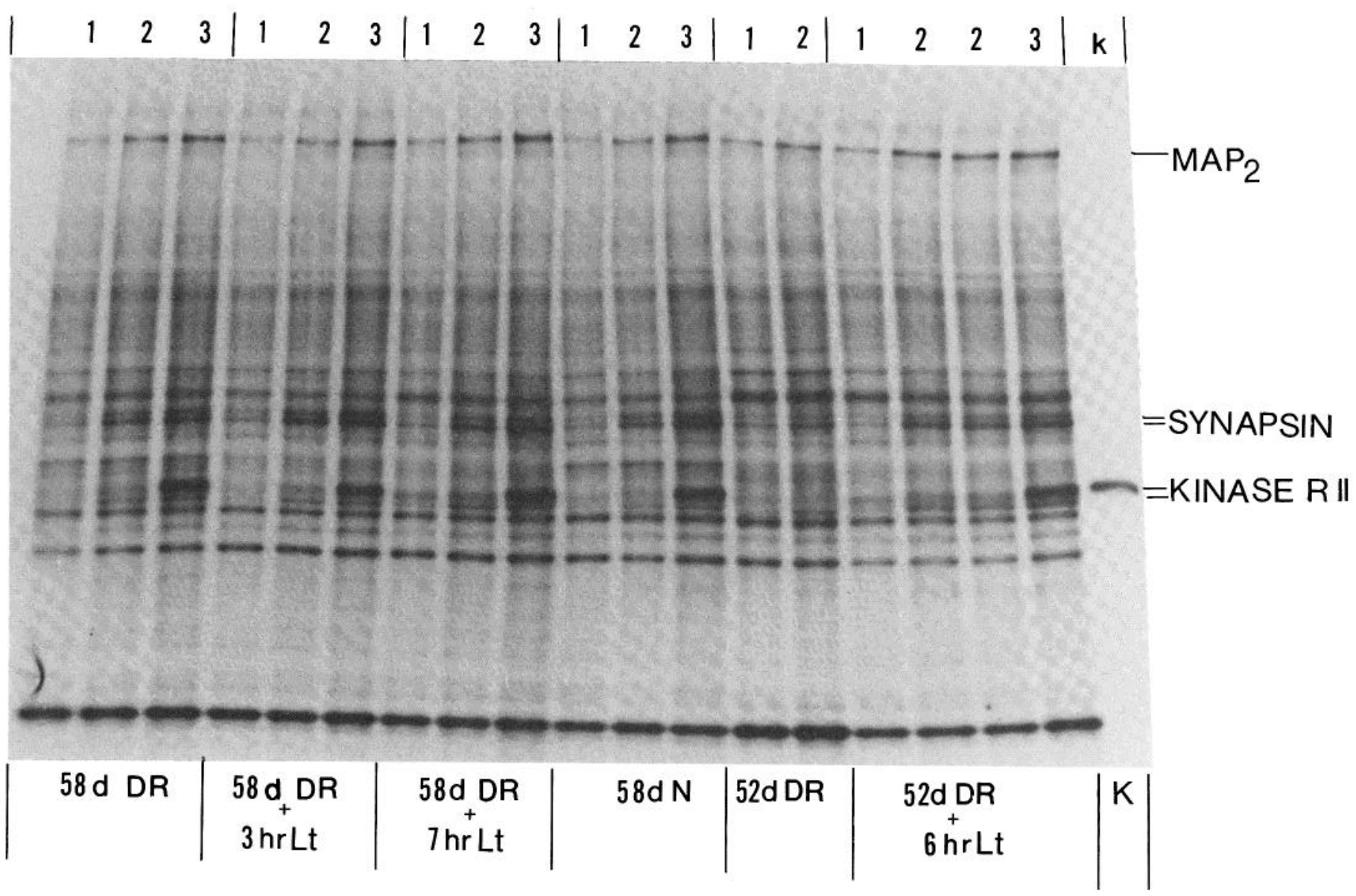

\section{G N}

Figure 9. The effect of the exposure to light following dark rearing on phosphorylation of MAP 2 in LGN. Phosphorylations were performed, gels were run, and autoradiograms were made as in "Materials and Methods." The following were added: lane 1 , nothing; lane $2,10^{-6} \mathrm{M}$ cAMP; lane $3,10^{-6} \mathrm{M}$ cAMP and bovine heart cAMP-dependent protein kinase ( 8 units). Lane $k$ contained no homogenate but did have cAMP and the bovine kinase.

MAP 2 phosphorylation in the auditory cortex following exposures to light. The autoradiogram in Figure 8 contrasts the light effect on the 52-day litter in the two cortical areas under the incubation condition which maximized de novo phosphorylation: although MAP 2 exhibited a greater than 2-fold enhancement in the phosphorylation in the visual cortex, there was no measurable difference between the dark-reared and dark-reared-plus-light littermates in the auditory cortex. Again, the phosphorylation of synapsin was little affected in either cortical area. The observations in the autoradiograms were further confirmed by counting ${ }^{32} \mathrm{P}$ incorporated into the protein bands with a scintillation counter, and comparing counts in the MAP 2 and synapsin bands from the visual and auditory cortices of animals under the different rearing conditions (Table III). For example, in the auditory cortex of the 52 -day litter, light exposure gave only $4 \%$ and $7 \%$ increases in the MAP $2 /$ synapsin ratio (Table III) and in another assay gave only $15 \%$ and $23 \%$ increases (data not shown), as compared to the $178 \%$ increase in the visual cortex of the same animal (Table III). In the case of the auditory cortex of the 59-day litter, there was a $3 \%$ decrease in the light-exposed animal (Table III), and in one other assay, there was a $4 \%$ increase (data not shown). 
TABLE IV

The effect of light exposure following dark rearing on the relative phosphorylation in the lateral geniculate nucleus of MAP 2, synapsin, and the regulatory subunit of the type /I CAMP-dependent protein kinase (R-II)

The values were obtained as described in Tables II and III. For the definitions of the abbreviations, see Table III. The autoradiograms from which the cpm values were obtained can be seen in Figure 9. The comparisons of all three phosphorylations within the 52-day DR litter were determined under incubation conditions not containing exogenous kinase.

\begin{tabular}{lllll}
\hline \multicolumn{1}{c}{ Tissue Source } & \multicolumn{1}{c}{ MAP 2 } & \multicolumn{1}{c}{ Synapsin } & \multicolumn{1}{c}{ R-II } & MAP 2/Synpasin \\
\hline 58-d DR & $1.00(263 \mathrm{cpm})$ & $1.00(562 \mathrm{cpm})$ & $1.00(516 \mathrm{cpm})$ & 1.00 \\
58-d DR + 3-hr Lt & 0.93 & 1.34 & 0.89 & 0.69 \\
58-d DR + 7-hr Lt & 1.00 & 1.20 & 0.90 & 0.83 \\
58-d NR & 1.00 & 1.38 & 0.74 & 0.72 \\
52-d DR & $1.00(211 \mathrm{cpm})$ & $1.00(681 \mathrm{cpm})$ & $1.00(550 \mathrm{cpm})$ & 1.00 \\
52-d DR + 6-hr Lt & 1.03 & 0.86 & 0.85 & 1.20 \\
\hline
\end{tabular}

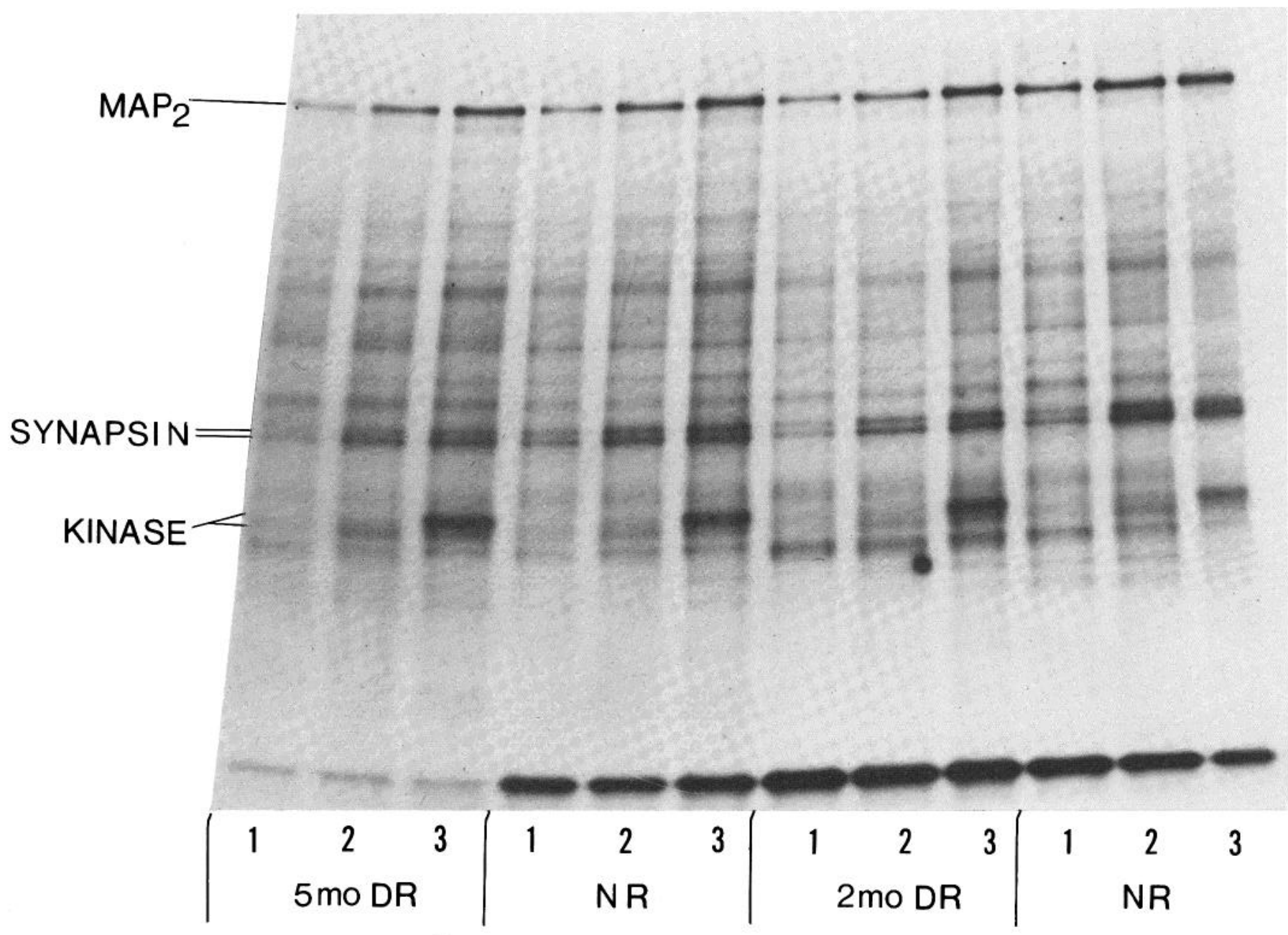

\section{ALL ADULTS, NORMALLY REARED DURING CP}

Figure 10. The effect of dark rearing during adulthood upon the phosphorylation of MAP 2 in visual cortex. Sexually mature, adult cats were normally reared through the critical period $(C P)$, followed by continued normal rearing $(N R)$ or by rearing in the dark for 2 months $(2$ mo $D R)$ or 5 months $(5$ mo $D R)$. Phosphorylations were performed, gels were run, and autoradiograms were made as described under "Materials and Methods." The following were added during the incubation for phosphorylation: lane 1, nothing; lane 2, $10^{-6} \mathrm{M}$ cAMP; lane $3,10^{-6} \mathrm{M}$ CAMP-dependent protein kinase.

We then wanted to address the question as to whether the enhanced cAMP-stimulatable phosphorylation of MAP 2 is related to the onset of the CP. For this, we chose to study the LGN, the thalamic relay nucleus between the retina and the primary visual cortex, since we could be certain that it received enhanced stimuli as did the visual cortex, but the stimulus does not affect the postnatal development of the LGN nearly as profoundly as it does the visual cortex (cf. reviews by Blakemore, 1974; Barlow, 1975; Movshon and Van Sluyters, 1981; Sherman and Spear, 1982). When the whole homogenates from the LGN of the dark-reared cats were compared to those of the light-exposed littermates, there was no measurable difference in the phosphorylation of MAP 2. Figure 9 shows the qualitative comparison and Table IV gives a quantitative comparison of phosphorylations of MAP 2 in the LGN from the same animals as those tested for visual cortex phosphorylation (cf. Fig. 6). For example, whereas MAP 2 phosphorylation in the 52-day dark-rearedplus-light cat exhibited a greater than $200 \%$ increase of the MAP 2/ synapsin ratio in the visual cortex (Table II), there was only a $20 \%$ 
TABLE $V$

Ihe effect in adulthood of dark rearing and of subsequent light exposure on the relative phosphorylation in the visual cortex of MAP 2, synapsin, and the regulatory subunit of the type /I CAMP-dependent protein kinase (R-II)

The normalized values of the cpm were obtained as described in Table II. The autoradiogram from which the cpm values in experiment I were obtained can be seen in Figure 10. The three animals in experiment II were from the same litter.

\begin{tabular}{|c|c|c|c|c|c|}
\hline & Tissue Source & MAP 2 & Synapsin & $R \cdot \|$ & MAP 2/Synapsin \\
\hline \multirow[t]{4}{*}{ I. } & Adult, 2-mo. DR ${ }^{a}$ & $1.00(661 \mathrm{cpm})$ & $1.00 \quad(752 \mathrm{cpm})$ & $1.00(623 \mathrm{cpm})$ & 1.00 \\
\hline & Adult, 5-mo. DR & 1.64 & 1.27 & 1.35 & 1.29 \\
\hline & Adult, never DR & 1.66 & 1.85 & $1 . / 2$ & 0.90 \\
\hline & Adult, never DR & 1.39 & 1.03 & 0.91 & 1.35 \\
\hline \multirow[t]{3}{*}{ ॥. } & $213-d N R+30 d d D$ & $1.00(379 \mathrm{cpm})$ & $1.00(1040 \mathrm{cpm})$ & $1.00(812 \mathrm{cpm})$ & 1.00 \\
\hline & $\begin{array}{l}\text { 213-d NR + 30-d DR } \\
\quad+3.5-\text { hr Lt }\end{array}$ & 0.84 & 1.00 & 0.74 & 0.84 \\
\hline & $\begin{array}{l}\text { 213-d NR + 30-d DR } \\
\quad+4.0-\mathrm{hr} \mathrm{Lt}\end{array}$ & 1.10 & 0.96 & 0.64 & 1.15 \\
\hline
\end{tabular}

${ }^{a} \mathrm{DR}$, dark reared; NR, normally reared; Lt, exposure to light; d, day.

TABLE VI

The effect of light exposure following dark rearing on a comparison between the concentration and phosphorylation of MAP 2 in the visual cortex homogenates of cats of different ages.

The phosphorylation values of MAP 2 were taken from Table II. From these same animals $300 \mu \mathrm{g}$ of tissue were used to quantitate by immunoblotting the amount of MAP 2, as described under "Materials and Methods." The linearity of the assay was indicated by a linear coefficient of 0.93 , using 0 to $400 \mu \mathrm{g}$ of adult visual cortex homogenate.

\begin{tabular}{|c|c|c|}
\hline Tissue Source & MAP 2 Phosphorylation & MAP 2 Concentration \\
\hline $52-\mathrm{d} \mathrm{DR}^{2}$ & $1.00(153 \mathrm{cpm})$ & $1.00(1080 \mathrm{cpm})$ \\
\hline 52-d DR + 6-hr Lt & 3.48 & 0.77 \\
\hline 52-d DR + 6-hr Lt & 3.38 & 1.27 \\
\hline 58-d NR & 3.58 & 0.72 \\
\hline 58-d DR & $1.00(381 \mathrm{cpm})$ & $1.00 \quad(855 \mathrm{cpm})$ \\
\hline 58-d DR + 3-hr Lt & 1.36 & 1.01 \\
\hline $58 \cdot d \mathrm{DR}+7 \cdot \mathrm{hr} \mathrm{Lt}$ & 1.43 & 2.40 \\
\hline 58-d NR & 1.44 & 0.90 \\
\hline 98-d DR & $1.00(257 \mathrm{cpm})$ & $1.00(925 \mathrm{cpm})$ \\
\hline $98-\mathrm{d} \mathrm{DR}+7 \cdot \mathrm{hr} \mathrm{Lt}$ & 2.18 & 1.25 \\
\hline 97-d NR & 1.11 & 1.62 \\
\hline
\end{tabular}

${ }^{a} \mathrm{~d}$, day; DR, dark reared; Lt, exposure to light; NR, normally reared.

increase in the LGN (Table IV), and whereas MAP 2 phosphorylation in the 58-day dark-reared-plus-light cat exhibited an $80 \%$ increase in the visual cortex, there were decreases of $17 \%$ and $31 \%$ in the LGN (Table IV), and in another assay there was a $17 \%$ increase (data not shown).

Effect of dark rearing in adulthood upon visual cortex phosphorylation. In order to indicate further the dependency on the CP for the observed MAP 2 phosphorylation results, the effect of dark rearing was examined in the visual cortices of two mother cats that were reared normally during the $\mathrm{CP}$ and subsequently dark-reared with the kittens for periods of 2 and 5 months. Direct comparisons were difficult here, since the adults were from different litters and were reared in a more varied environment during the CP. Nevertheless, when compared with the adult cats that were never reared in the dark, there were no consistent changes in the MAP 2/synapsin ratios between the normally reared animals and the normal, then dark-reared animals (Fig. 10, Table V, experiment I). Furthermore, the role of visual cortex plasticity on the effect of exposure to light following long-term dark adaptation was examined. For this, a litter reared under normal light environment for 213 days from birth was put in the dark-rearing box for 30 days, then exposed to $0,3.5$, or 4 $\mathrm{hr}$ of light just before sacrifice. It was found that ${ }^{32} \mathrm{P}$ incorporated into MAP 2 had ratios of 1.00:0.84:1.10, and 1.00:0.84:1.15 before and after, respectively, normalizing for the degree of ${ }^{32} \mathrm{P}$ incorporation into synapsin (Table V, experiment II). These results indicate that the enhanced MAP 2 phosphorylation is not caused solely by the change in light stimulus but reflects the effect of deprivation and stimulation delimited to the $\mathrm{CP}$.

Effect of exposure to light following dark rearing on concentration of MAP 2 in visual cortex. Finally, to answer the question of whether the observed MAP 2 phosphorylation results were due to changes in the phosphorylated state of MAP 2 or to changes in the concentration of MAP 2, a quantitative immunoblot assay was performed, as described under "Materials and Methods," on the same visual cortex tissues from which the phosphorylation results were obtained (cf. Table II). Table VI indicates that, by and large, there was no correlation between the phosphorylation changes and concentration changes in these tissues. Thus, in two sets of animals, dark rearing resulted in a decrease in cAMP-stimulatable MAP 2 phosphorylation but an increase in the concentration of MAP 2. In all three sets, a subsequent exposure to light of the dark-reared animal did result in an increase in the concentration of MAP 2 but not nearly as much as an increase in the phosphorylation of MAP 2, with one exception. Because of the difficulty in quantitation of the immunoblot assay on tissue samples, such as making sure of adequate penetration of the antibody, even in the presence of Triton X-100 (cf. "Materials and Methods"), we can only tentatively state that the phosphorylation results were not due to changes in MAP 2 content in the visual cortex cortices of the various animals.

\section{Discussion}

We have used the visual system of cats to study the biochemical basis for plasticity of neuronal connectivity. It has been reconfirmed by many laboratories during the past two decades that, as Hubel and Wiesel (1970) first reported, there is a critical period (CP) during which visual experience molds permanently some aspects of visual function. This period spans the first through the fourth month in cats and about month 4.5 through the third year in humans (Banks et al., 1975; Hohmann and Creutzfeldt, 1975; Petrig, et al., 1981). The aspects of the visual functioning which are susceptible to changes include acuity, orientation tuning, directional tuning, and ocular dominance (cf. reviews by Blakemore, 1974; Barlow, 1975; Movshon and Van Sluyters, 1981; Sherman and Spear, 1982). In short, it appears that the receptive field properties of the visual cortex neurons can undergo plastic changes during the $\mathrm{CP}$ which mirror experience. It is not known how the microcircuitry of the visual cortex is laid down during development, which elements are involved, and in what ways these elements are affected in response to the stimuli presented to the system. This inquiry has been difficult, since the microcircuitry of the normal adult visual cortex is not yet fully understood (cf. review by Gilbert, 1983).

We have instead pursued the understanding of the conditions permissive for plasticity during the CP. The results from Cynader's laboratory (Cynader et al., 1976; Cynader and Mitchell, 1980; Timney et al., 1980) indicate that the CP itself is subject to change, as can be observed by the ocular doinance shift that occurs in cats well 
beyond the $\mathrm{CP}$ so long as they have been completely deprived of light stimulation prior to the sessions of monocular deprivation (monocular stimulation). Furthermore, the results from Cynader's laboratory have been confirmed by Mower et al. (1981a, b), and this group has also recently reported (Mower et al., 1983) that the effect of dark rearing is reversed by a few hours of exposure to light during the dark-rearing period. Mower et al. (1983) have interpreted thesc results to indicate that the onset of the $C P$ requires the presence of visual stimulation, but once started, the process of neuronal development proceeds with a genetically predetermined time course, irrespective of the condition of the environmental light stimuli. Thus, it appears that light is a necessary component to trigger the onset of the changes in the visual cortex to render it permissive for molding according to experience

The second aspect of the permissive conditions for plasticity has been investigated by Kasamatsu and his colleagues (Kasamatsu, 1979, 1980; Kasamatsu and Pettigrew, 1976, 1979; Kasamatsu et al., 1979, 1981a, b, 1983; Pettigrew and Kasamatsu, 1978). They have observed that the local level of $I$-norepinephrine (NE) can determine the responsiveness of the cortical neurons to deprivation. When the local NE was depleted by the use during the CP of a neurotoxin, $6-\mathrm{OHDA}$, the ocular dominance shift normally observed was prevented (Kasamatsu and Pettigrew, 1976; Kasamatsu et al., 1981b). When such lesioned animals and animals beyond the CP were perfused with exogenous NE (Pettigrew and Kasamatsu, 1978; Kasamatsu and Pettigrew, 1979; Kasamatsu et al., 1979, 1981a, b) or stimulated in the locus ceruleus (Kasamatsu et al., 1983) where the noradrenergic fibers originate, plasticity could be restored. Kasamatsu et al. (1981a) estimated that $3 \times 10^{-7} \mathrm{M} \mathrm{NE}$, or about 200 ng of NE/gm of wet weight cortex, is sufficient to restore plasticity in a 6-OHDA-lesioned cortex. The results with 6-OHDA have been corroborated by others (Daw et al. 1981, 1983; Bear et al., 1983), who at the same time also point out the particularity of the effect Thus, when the lesion is administered more generally within the brain (Daw et al., 1984a, b) or chronically from birth (Bear and Daniels 1983; Bear et al., 1983), plasticity is not altered. As these authors have noted, every monoamine lesion is complicated by the supersensitivty response that compensates for the lowered concentration of the neurotransmitter released at synapses: furthermore, the phenomenon itself is complicated by its variable degree and time course. When the neurotoxin is administered generally, it is even possible that supersensitivity is provoked in some sites and not in others, as has been observed in rat brains (Reisine et al., 1979). It is even conceivable that the monoamines may have opposing effects upon plasticity in the retina, the LGN, and the visual cortex throughout ontogeny. Whether the different effects among all of these authors and their colleagues result from differences in the lesioned anatomical sites or in the state of supersensitivity is not certain. In considering the developing and supersensitized cat brains, there is not enough known to be able to speculate whether the residual 10 to

\% of NE could be sufficient to permit plasticity in the visual cortex. It nould also be noted that the extent of 6-OHDA lesions is variable, depending on the dosage, the state of the animal, and the site of injection of the toxin. In fact, the treatment is occasionally lethal, when administered generally, as has been observed in this laboratory as well as by J. D. Daniels (personal communication). We therefore consider that the evaluation of the data of ocular dominance shift should be focused upon those in which the monoamine depletions were localized within the visual cortex and also quantitatively confirmed within the same animal. We must await further experimental results which test the supersensitivity in the lesioned kitten brains as well as other assessments of the restoration of plasticity in adult brains with exogenous NE, and not by other neurotransmitters, before we can be certain of the role of NE upon plasticity

In the meantime, preliminary results (Kasamatsu, 1979) indicate that the action of NE is mediated via $\beta$-adrenergic receptors, since blocking the $\beta$-receptors with propranolol blocked the effect of NE. The $\beta$-Adrenergic receptor is characterized by the ability to couple to a transmembrane enzyme, adenylate cyclase, that converts ATP to cAMP intracellularly. For this reason, Kasamatsu (1980) tried perfusing the occipital cortex with dibutyryl-cAMP, a membranepermeble analogue of CAMP, and reported that this also restored plasticity in 6-OHDA-lesioned brains.

Based upon these observations, we reasoned that if NE does play a role in determining plasticity of the visual cortex, then there must be changes in the NE-stimulatable cAMP metbolism during ontogeny which cause changes in the state of plasticity of the normal neocortex. We have addressed this question by shifting the onset of the CP by dark-rearing kittens from birth followed by 3 to 7 hr of exposure to light. We have then looked for biochemical changes which may have been concomitantly shifted. We have examined the ontogeny of adenylate cyclase during normal rearing, following dark rearing, and following exposures to light after dark rearing. The results (Aoki and Siekevitz, 1982, 1983; C. Aoki and P. Siekevitz, manuscript in preparation) indicate that the entire cyclase system, which includes the catalytic subunit, the hormone receptor, and the GTP-binding subunit which couples the receptor to the catalytic subunit, are modulated in synchrony during development. The specific activities increase throughout the critical period and plateaus beyond. When the animal is dark reared, the specific activity is slightly enhanced and remains at that level after a few hours of exposure to light. In contrast, cyclic nucleotide phosphodiesterase, which hydrolyzes cAMP, appears not at all modulated by dark rearing: under all three rearing conditions, its specific activity reaches the adult level within a month and plateaus beyond. Taken together, the results suggest that the rate of turnover of CAMP increases from birth up to the first postnatal month, at which approximate time the $\mathrm{CP}$ begins, and that the concentration of CAMP then increases gradually during the $\mathrm{CP}$. Neither the concentration nor the rate of turnover of CAMP diminishes beyond the CP.

In this paper, we have found that similar patterns are observed in the case of the cAMP-stimulated phosphorylation of protein R-II. This protein and also protein R-I, which are the regulatory subunits of type II and type I cAMP-dependent protein kinases, were identified by the co-migration on SDS-gels of the phosphoproteins and the 8 $\mathrm{N}_{3}$-cAMP-binding bands according to the procedure of Pomerantz and his colleagues (Walter et al., 1978; Rangel-Aldao et al., 1979; Pomerantz et al., 1980) as can be seen in Figure 3. By comparing in the SDS-gels ${ }^{32} \mathrm{P}$ incorporated into the subunits and by the binding of ${ }^{32} \mathrm{P}-8-\mathrm{N}_{3}-\mathrm{CAMP}$ onto the RI and R-\|l subunits, higher concentrations of both subunits are found in whole homogenates of 1-week-old visual cortices than in those from older brains (data not shown). This pattern can be interpreted to mean that, whereas the kinases have attained adult levels by birth, other protein species, whether or not they are neuron specific, are continuing to increase as the brain grows, thus decreasing the relative content of the kinases per 100 $\mu \mathrm{g}$ of whole homogenate proteins. Investigations using tissue culturcs have long implicated the involvement of the phosphorylation of phosphoproteins in many aspects of development, such as the switching off of mitosis and the subsequent initiation of cellular differentiation (cf. Nathanson, 1977, for review). Since most of the neuronal precursors have undergone their terminal mitosis prenatally in primates (Rakic, 1974, 1977), and probably also in cats, is it not surprising that the CAMP- and $\mathrm{Ca}^{2+} /$ calmodulin-stimulatable phosphorylations are already present at birth and that the enzymes seem to be fully active.

Synapsin, the $80 / 86-\mathrm{kD}$ doublet, is another protein which we followed through ontogeny. This $80 / 86-\mathrm{kD}$ doublet was first identified by Ueda and Greengard (1977) and, by immunocytochemical methods, was found to be in highest concentration on the surface of synaptic vesicles (De Camilli et al., 1983), confirming earlier results from this laboratory (Ueda et al., 1979) and from that of $F$. E. Bloom et al., (1979), the latter laboratories also finding this protein to bc to a lesser extent also associated with postsynaptic densities (but cf. De Camilli et al., 1983). Clearly, it is a phosphoprotein enriched at synapses. In our experiments, the $80 / 86 \mathrm{kD}$ doublet was identified 
as synapsin by three criteria: (1) its co-migration with the doublet in the $80-\mathrm{kD}$ region of postsynaptic density preparations, previously identified as synapsin (Ueda et al., 1979) (cf. Fig. 5); (2) its phosphorylation which is stimulated by the addition of CAMP (Ueda and Greengard, 1977; Lohmann et al., 1980); and (3) its phosphorylation which is stimulated by $\mathrm{Ca}^{2+} /$ calmodulin (Kennedy and Greengard, 1981) (cf. Гig. 2). It was found that the phosphorylation of synapsin is very low at birth, increases during the first month, and then plateaus beyond. We believe that this change reflects a rise in synapsin content per milligram of protein rather than an increase in phosphorylatable sites of a constant concentration of protein. It may be that the enhanced in vitro phosphorylation reflects enhanced dephosphorylation that occurred during the period after the excision of the visual areas and before freezing of homogenates, which spans a period of about $10 \mathrm{~min}$ at $4^{\circ} \mathrm{C}$. This process could not be biochemically prevented, since there are no known specific phosphoprotein-phosphatase inhibitors. However, since age-matched animals exhibited extents of in vitro phosphorylation very close to one another, the contribution to variabilities by this process appeared less than the ontogenetic changes observed. Also, attempts to dephosphorylate the proteins by preincubating at $30^{\circ} \mathrm{C}$ for up to 1 $\mathrm{hr}$ in the absence of ATP did not measurably increase its subsequent phosphorylation (data not shown), indicating that it is already stably dephosphorylated either in vivo or due to the manipulations involved in preparing the whole homogenates. It can alternatively be interpreted that this change reflects the ontogenetic change in the dephosphorylating enzyme. We believe this not to be the case, also, since the ontogenetic pattern is observed in the presence of an excess of exogenous CAMP-dependent protein kinase and optimal concentration of CAMP, so that this pattern reflects the state of maximal phosphorylation which is probably overwhelmingly greater than the rate of dephosphorylation. It is interesting that the changes through ontogeny of the phosphorylation of synapsin (Fig. 5), which is concentrated at synapses, correlates temporally, although not quantitatively, with the ontogenetic changes in synapse density in the visual cortex of cats as determined by morphometric analyses (Cragg, 1972). Its phosphorylation is probably strongly and rapidly modulated by changes in the intracellular environment, as can be observed by the in vitro enhancement in its phosphorylation by increased $\mathrm{Ca}^{2+}$ and cAMP. Its fibrous morphology (Ueda and Greengard, 1977) suggests its role as part of the cytoskeleton to perhaps control movements of vesicles (De Camilli et al., 1979), but how such a mechanism might be dependent on the state of phosphorylation of the molecule is entirely unknown at the present time. Its cAMP-stimulatable phosphorylation is not affected by the animal's dark rearing (Fig. 5, Table I) or by its exposures to light (Fig. 6, Table Ii). In agreement with this, wo have not obscrved any measurable influence of dark rearing and the subsequent exposures to light upon the frequency of synapses per volume of cortex in any of the cortical layers (unpublished data)

The other phosphoprotein examined in the visual cortex whole homogenates has been identified as MAP 2 by three criteria: (1) the stimulation of its phosphorylation by CAMP (Figs. 2 to 10); (2) its reactivity to four MAP 2-monospecific antisera from two laboratories (Fig. 4) and (3) its migration pattern in SDS-gels (Figs. 2 to 10). ${ }^{3}$ MAP 2 has been reported to be phosphorylated by a $\mathrm{Ca}^{2+} /$ calmodulin-dependent kinase semipurified from rat brain cytosol (Bennett et al., 1983; Goldering et al, 1983; Yamamoto et al., 1983; Schulman, 1984). In our case, although we do see $\mathrm{Ca}^{2+} /$ calmodulin-stimulated

\footnotetext{
${ }^{3}$ We have obtained further support for the identification of the high molecular weight phosphoprotein as MAP 2. A similar heat-stable property as that of MAP 2 (Kim et al., 1979) was also found for our phosphoprotein, by boiling the tissue, and observing that a protein in the supernatant was phosphorylated by exogenous CAMP-dependent protein kinase, and that this phosphoprotein migrated on SDS-geis to the position of the phosphorylated MAP 2
}

phosphorylation of synapsin and the major $51-\mathrm{kD}$ substrate (Grab et al., 1981), we could not find any stimulation of phosphorylation of MAP 2 by the addition of $\mathrm{Ca}^{2+} /$ calmodulin. Also, when the homogenate was incubated with up to $5 \mathrm{~mm}$ EGTA in the attempt to prevent any phosphorylation induced by the endogenous $\mathrm{Ca}^{2+} /$ calmodulin in the homogenate, there was observed no depression in the phosphorylation of MAP 2. The reason for this discrepancy is not known, although it may have to do with differences in animals, in brain areas tested, in the presence of phosphatases in whole homogenates which specifically dephosphorylate certain sites in MAP 2, or in the possibility that the phosphorylatable sites in MAP 2 which are stimulated for phosphorylation by $\mathrm{Ca}^{2+} /$ calmodulin are already maximally phosphorylated in vivo, and cannot be increased by in vitro phosphorylation.

The most significant finding reported here is that, in contrast to the phosphoproteins, synapsin, and R-ll, discussed above, the CAMP-stimulatable phosphorylation of MAP 2 within the visual cortex is strongly dependent on visual stimulation, so that following 2 months of dark rearing during the $\mathrm{CP}$, its phosphorylation is diminished in comparison to that of the age-matched normally reared kittens (Table I, Fig. 5), and this decrease is reversed by short exposures to light (Table II, Fig. 6). When the phosphorylation of the proteins from other dark-reared cats is compared to that of their littermates who were exposed to light, an enhancement, by light exposure, of MAP 2 phosphorylation is observed consistently across the three 2-month dark-reared, one 3-month dark-reared, and one 5month dark-reared litters. This effect of visual stimulation is not observed in auditory cortex homogenates prepared from the same animals. We interpret this result to mean that the effect is not caused simply by arousal but reflects a specific response involving an onset of the CP triggered by sensory stimulation following complete deprivation. It was also observed that dark rearing or re-exposure to light following dark rearing had no effect upon phosphorylation in the visual cortex of adult cats normally reared during the first 7 months, suggesting that the activity-dependent changes in MAP 2 phosphorylation depended on the state of plasticity of the brain areas. In contrast, it is interesting that the enhancement by light exposure of phosphorylation of MAP 2 was observed in the visual cortex of a kitten which had been dark-reared from birth for 5 months, which, by chronological age, was well beyond its $\mathrm{CP}$. This finding is significant, since the visual cortex, due to the complete deprivation of light from birth, could still be triggered at 5 months for the onset of the critical period (Cynader and Mitchell, 1980), and we may be observing an aspect of this delayed onset event in the enhancement of MAP 2 phosphorylation. The LGN, which is as visually stimulated as the visual cortex, unexpectedly did not appear nearly as responsive to the stimulation in its MAP 2 phosphorylation pattern (Table IV, Fig. 9). Previous studies of the LGN have reported that, following monocular deprivation, there is a 30 to $49 \%$ decrement in soma size within the deprived layers of the binocular segments as compared to the adjacent non-deprived layers (Wiesel and Hubel, 1963b), but with no dramatic electrophysiological effects (Wiesel and Hubel, 1963b; Shapley and So, 1980; but also cf. Friedlander et. al., 1982, and a review by Sherman and Spear, 1982). From such observations, the effect of the soma size has been interpreted to be reflective of the differences in the axonal arborization of these neurons, the target zones of which are the visual cortex, and that the LGN itself does not have a postnatal $\mathrm{CP}$. Thus, our finding of a difference in the MAP 2 phosphorylation pattern between the visual cortex and the LGN may be reflective of this difference in plasticity between these two visual areas.

The decreases in cAMP-stimulatable phosphorylation of MAP 2 in the dark-reared animals and subsequent increases following light exposures may reflect one or more of the following changes: (1) changes in the activitics of proteases directed against MAP 2; (2) changes in the extent of dephosphorylation that have occurred during homogenization; (3) that there were differences among the tissues from the variously reared animals in their amount of ATPase 
activity; (4) change in the concentration of the phosphoprotein itself; (5) a change in the cAMP-stimulated in vitro phosphorylatable sites due to the in vivo dephosphorylation/phosphorylation activities; or (6) a change in the phosphorylatable sites due to possible conformational changes in the protein molecule. To minimize the effect of change 1 , homogenization was always done rapidly (for $10 \mathrm{~min}$ at $4^{\circ} \mathrm{C}$ before freezing). Also, $10 \mu \mathrm{g}$ of leupeptin/ml was used, en to inhibit $\mathrm{Ca}^{2+}$-activated protease activity (Toyo-oka et al., 1978; Baudry et al., 1981). With respect to point 2 , we have already dealt with this above. It is difficult to be able to distinguish event 5 from event 6 , but we have attempted to address the possibility of events 3 and 4 happening. With regard to possibility 3 , we have observed that the reported differences and similarities in MAP 2 phosphorylation persisted when the protein concentration was decreased from $100 \mu \mathrm{g}$ down to $30 \mu \mathrm{g}$, (decreasing the possible endogenous ATPase), and when the ATP concentration was raised from $10 \mu \mathrm{M}$ to $100 \mu \mathrm{M}$ (resulting in an increase in MAP 2 phosphorylation). Also, it is important to notice that the degree of synapsin I phosphorylation was approximately the same in all of the experiments using tissue from age-matched animals, indicating that the ATPase activity was probably similar in all of these cases. We have directly compared the relative content of MAP 2 per milligram of protein in the whole homogenates from the various dark-reared and normally reared litters by blotting the homogenates on nitrocellulose papers, and reacting them with a monoclonal antiserum against MAP 2 . When the reactive antibody was then quantified by binding it subsequently with a second antibody and radioactive protein $A$, the results indicated that the changes in the content of MAP 2 were not sufficient to account for the changes in phosphorylation in vitro (Table IV). Thus, with these cautionary provisions in mind, it still appears that the decreased cAMP-stimulated in vitro phosphorylation after dark rearing indicates a more cAMP-stimulatable phosphorylated state of MAP 2 in vivo as compared to normally reared animals. The enhanced CAMP-stimulated in vitro phosphorylation observed following exposure to light would then indicate that light exposure results in a whole or partial dephosphorylation of CAMP-stimulated sites in MAP 2 in vivo.

What might be the functional significance of the observation of the state of cAMP-stimulatable MAP 2 phosphorylation? MAP 2 is a neuron-specific (Izant and Mclntosh, 1980), microtubule-associated protein which co-purifies with tubulin polymerized in vitro (cf. review by Snyder and McIntosh, 1976). When MAP 2 is purified and incubated in the presence of polymerized tubulin, it is found periodically associated with tubulin (Herzog and Weber, 1978) at a periodicity of $32 \pm 8 \mathrm{~nm}$ (Murphy and Borisy, 1975; Kim et al., 1979). Its presence is necessary for nucleation and subsequent polymerization of tubulin into microtubules in vitro (Murphy and Borisy, 1975; Sloboda et al., 1976; Murphy et al., 1977; Herzog and Weber, 1978; Vallee et al., 1981). Others have reported the roles of MAP 2 in aiding the cross-linking of microtubule to actin (Griffith and Pollard, 1978; Seldon and Pollard, 1983) and in being able to organize actin molecules into filament bundles (Sattilaro et al., 1981). There are also reports of its cross-linking to neurofilaments (Pytela and Wiche, 1980; Rice et al., 1980; Leterrier et al., 1982; Bloom and Vallee, 1983). Clearly, MAP 2 seems to be an indispensable protein for the control of the organization of the cytoskeletal structure within neurons.

The studies on the localization of MAP 2 by immunocytochemical approaches have shown brain MAP 2 to exist to some extent in axons (Caceres et al., 1984a) but concentrated much more in dendrites (Matus et al., 1981; Burgoyne and Cumming, 1983; Caceres et al., 1983, 1984a, b; Bernhardt and Matus, 1984; Bloom et al., 1984; Huber and Matus, 1984a). Since neurofilament is much more an axonal than a dendritic cytoskeletal protein (Cumming and Burgoyne, 1983), MAP 2 would appear to be associated more with microtubules and/or actin in dendrites. During development, the appearance of MAP 2 precedes that of the dendritic microtubules (Bernhardt and Matus, 1982). From this observation these authors have suggested that MAP 2 may play a role in the elaboration of dendrites during normal neuronal differentiation, such as the setting up of the scaffolding for microtubules or the control of microtubulemediated cytoplasmic transport and pinocytoses. Another role for MAP 2 in dendrites is its possible involvement with the actin in dendritic spines (Matus et al., 1982; Fifková and DeLay, 1982) in oryanizing the cytoskeleton there. It is unclear whether or not MAP 2 itself is particularly localized in the spines (Matus et al., 1982; Caceres et al., 1983; Bernhardt and Matus, 1984), but it is conceivable in either case that the control of the cytoskeletal cross-linking and branching pattern might involve MAP 2 association with either actin or microtubules, or both, at the base of the spine.

There is less known about the role of phosphorylation of MAP 2, although this post-translational modification is probably very important, as can be guessed from the intricate association of MAP 2 with a CAMP-dependent protein kinase (Leterrier et al., 1974; Shigekawa and Olsen, 1975; Sloboda et al., 1975; Soifer et al., 1975; Rappaport et al., 1976; Sheterline, 1977; Theurkauf and Valee, 1982). According to Theurkauf and Vallee (1982), there is one molecule of the type ॥ cAMP-dependent protein kinase holoenzyme co-purifying with 40 molecules of MAP 2, indicating that as much as one-third of the total cytosolic CAMP-dependent kinase is bound to MAP 2. Both the MAP 2 domain that anchors onto microtubules and the domain that projects from it contain phosphorylation sites (Theurkauf and Vallee, 1983), suggesting that the phosphorylation of MAP 2 can alter its role in the cross-linking of cytoskeletal proteins. Furthermore, their results indicate that as many as 13 sites are phosphorylated in the presence of cAMP and that 8 sites are not CAMP dependent. These 8 sites may be the $\mathrm{Ca}^{2+}$ /calmodulin-stimulated ones (Bennett et al., 1983; Goldering et al., 1983; Yamamoto et al., 1983; Schulman, 1984), which do not seem to be involved in the visual stimulation. Since the regulatory subunit of type II cAMP-dependent protein kinase coexists with MAP 2 in dendrites (Miller et al., 1982), this event may occur rapidly and be localized to a particular synapse.

The phosphorylation of MAP 2 appears to reduce its association with microtubules (Murthy and Flavin, 1983) and inhibit microtubule assembly without changing the critical protein concentration for polymerization (Jameson et al., 1980, Jameson and Caplow, 1981; Murthy and Flavin, 1983). Phosphorylation also seems to inhibit its interaction with actin (Nishida et al., 1981; Seldon and Pollard, 1983). Overall, phosphorylation of MAP 2 appears to be the key for the disassociation of the cytoskeletal structure, an event inevitable with changes in cell shape which in turn must accompany changes in neuronal connectivity. Thus, our in vitro phosphorylation data, which showed lowered CAMP-stimulated phosphorylation of MAP 2 following dark rearing, may reflect a more phosphorylated MAP 2 in vivo, suggesting the existence of a relatively uncross-linked malleable state of the cytoskeletal structure. Analogously, the enhanced phosphorylation observed following exposures to light may reflect a more dephosphorylated state of MAP 2 within the stimulated neuronal pathways, suggesting that the cytoskeletal structure of the scaffolding for the dendrites has been formed.

The biochemical events regulating intracellular cAMP have been reported to regulate long-term neuronal functions in various systems. For example, mutations in the enzymes involved in cAMP metabolism for Drosophila melanogaster have been linked to alterations in their lifetime learning abilities (Byers et al., 1981; Livingstone et al., 1984). In the nervous system of Aplysia californica, a hormone-stimulated rise in intracellular cAMP has been causally linked to the formation of long-term memory (Kandel and Schwartz, 1982). These authors speculate that long-term changes in the efficacy of synaptic transmission might involve a quantitative or conformational change in the regulatory subunit of the CAMP-dependent protein kinase. Since this case of long-term memory involves an increase in the area of the active zone, it might alternatively be postulated that such morphological changes involve changes in the state of phosphorylation and, thus, of the allosteric conformation of MAP 2, thus mediating dramatic and long-term changes in the cytoskeletal structure there. In 
tissue cultures, cAMP has been reported to induce fibroblast cell organization (Kram and Tomkins, 1973) neuronal cell shape (Roisen et al., 1972), neurite extension (Roisen and Murphy, 1973), and microtubule assembly in melanoma cells (DiPasquale et al., 1976). Since tubulin is not phosphorylated in a cAMP-dependent manner (Rappaport et al., 1972, 1976; Shigekawa and Olsen, 1975; Sloboda et al., 1975; Sheterline, 1977), again it may be that the reported effects are mediated by the enhanced phosphorylation of MAP 2.

The series of experiments reported here was stimulated by the reports by Kasamatsu and his colleagues (Pettigrew and Kasamatsu, 1978; Kasamatsu, 1980; Kasamatsu et al., 1979, 1981a, b, 1983) that the local concentration of NE binding to the $\beta$-adrenergic receptor might be influencing the state of plasticity of the visual cortex. If so, it may be that the ocular dominance shift observed following perfusion with dibutyryl-CAMP (Kasamatsu, 1980) or NE (Pettigrew and Kasamatsu, 1978; Kasamatsu et al., 1979, 1981a, b) and stimulation of locus ceruleus (Kasamatsu et al., 1983) might have been mediated via the enhancement of the MAP 2 phosphorylation. Specifically, this phosphorylation may have led to the momentary release of the cytoskeletal scaffolding leading to the reorganization of the cytoskeleton, which could permit changes in synaptic connectivity underlying the ocular dominance shift.

What might determine the end of the critical period in cat visual cortices? The process of maturation of the visual cortex can be described as the formation of synaptic contacts in accordance with experience, which become more difficult to reverse with time. But since exogenous NE seems to be able to make the synaptic contacts again plastic in adulthood (Pettigrew and Kasamatsu, 1978), even though endogenous NE is present at this age (Jonsson and Kasamatsu, 1983), the process of maturation may involve quantitative rather than qualitative changes in the molecular species determining the state of plasticity. One possibility is that the density of the $\beta$ adrenergic receptors increases postnatally (Jonsson and Kasamatsu, 1983; Shaw et al., 1985) and peaks within the CP followed by a decline (Jonsson and Kasamatsu, 1983); however, Shaw et al. (1984) did not discern this peaking within the CP. In this connection it is interesting that in the nonlesioned animals, $\mathrm{GABA}_{B}$ receptors have been found to modulate the NE-stimulated production of CAMP (Karbon et al.,1984), and that the $K_{D}$ for GABA binding to cat visual cortex is dramatically decreased during the critical period (Shaw et al., 1984), suggesting that the $G A B A_{B}$ receptors could be responsible for any change in sensitivity of the NE receptors.

Our results suggest that MAP 2 may also be undergoing changes with age. For example, whereas the MAP 2 from 2-month darkreared visual cortices showed less phosphorylation in vitro in comparison to that from the 2-month normally reared animal, implicating a more phosphorylated state in vivo due to dark rearing, the in vitro phosphorylation of MAP 2 did not diminish in the adult cats that were dark-reared for equivalent periods of time. Presumably, the MAP 2 of these adults that were dark-reared in adulthood have undergone at least one phosphorylation/dephosphorylation cycle during its critical period while they were exposed to normal light environments. It may be that MAP 2, upon neuronal stimulation, which here was evoked by light, undergoes cAMP-stimulated phosphorylation and subsequent dephosphorylation which are accompanied by conformational changes in the molecule to render it less accessible for further phosphorylation, when compared to the MAP 2 of dark-reared immature cortices that have not yet undergone the phosphorylation/dephosphorylation cycle. It is interesting that during maturation of rat brain there were postulated to be changes in the phosphorylation pattern of MAP 2 (Binder et al., 1984), as well as changes in the ability of MAP 2 to cause an assembly of tubulin (Francon et al., 1982). However, the correlation between the postulated increase during development in MAP 2 phosphorylation (Binder et al., 1984) and the increased ability to polymerize tubulin (Francon et al., 1982) does not jibe with earlier reports (cf. above) which correlated directly the unphosphorylated state of MAP 2 with the increased tubulin polymerization ability of MAP 2. Furthermore, in studies using rodents (Rose et al., 1976), the rate of tubulin turnover is lower in dark-reared than in normally reared rats but increases 2fold within the first hour after light exposure. It may be that these changes also occur in cat visual cortices as well, concomitant with the change in the state of phosphorylation of MAP 2. Finally, there have been various reports on the effects of light deprivation and of re-exposure to light on neuronal architecture. In rats, the number of synapses on a neuron was decreased in the visual cortex following sensory deprivation (Cragg, 1975), whereas when rats were first exposed to light there occurred an increase in the formation of new synapses (Cragg, 1967).

Studies of the dendritic arborizations of the visual cortices of darkreared rats show that the apical dendrites of layer $V$ pyramidal cells, which traverse layer IV, have reduced frequency of spines as compared to those from normally reared cats (Valverde, 1967), but a subpopulation of them exhibits rapid recovery following exposure to light (Valverde, 1971). This is particularly interesting in view of the finding by De Camilli et al. (1984), that the highest concentration of MAP 2 within the neocortex is also in the apical dendrites. It may be speculated that the changes in spine density observed by Valverde (1967, 1971) are mediated by the phosphorylation of MAPs decorating the microtubules within the dendrites, and which may promote the protrusion of spines.

Further speculation regarding the role of MAP 2 phosphorylation in visual cortical plasticity can only be answered by the results from in vivo experiments, such as inducing somehow the phosphorylation/ dephosphorylation of MAP 2 during ontogeny and during dark/light exposures.

\section{References}

Aoki, C., and P. Siekevitz (1982) The ontogenetic changes in metabolism of cAMP in the visual cortex of cals. Suc. Neurusci Abstr. 8: 4

Aoki, C., and P. Siekevitz (1983). The effect of dark-rearing upon cAMP. metabolism in the visual cortex of cats. Soc. Neurosci. Abstr. 9: 911.

Aoki, C., and P. Siekevitz (1984). Enhanced phosphorylation of microtubuleassociated protein, MAP 2, in the cat visual cortex during the critical period. Soc. Neurosci. Abstr. 10: 1078.

Banks, M. S., R. N. Aslin, and R. D. Letson (1975) Sensitive period for the development of human binocular vision. Science 190: 675-678.

Barlow, H. B. (1975) Visual experience and cortical development. Nature 258: $199-204$.

Baudry, M., M. C. Bundman, E. K. Smith, and G. S. Lynch (1981). Micromolar calcium stimulates proteolysis and glutamate binding in rat brain synaptic membranes. Science 212: 937-938.

Bear, M. R., and J. D. Daniels (1983) The plastic response to monocular deprivation persists in kitten visual cortex after chronic depletion of norepinephrine. J Neurosci. 3: 407-416.

Bear, M. R., M. A. Paradiso, M. Schwartz, S. B. Nelson, K. M. Carnes, and J. D. Daniels (1983) Two methods of catecholamine depletion in kitten visual cortex yield different effects on plasticity. Nature 302: 245-247.

Bennett, M. K., N. E. Erondu, and M. B. Kennedy (1983) Purification and characterization of a calmodulin-dependent protein kinase that is highly concentrated in brain. J. Biol. Chem. 258: 12735-12744.

Bernhardt, R., and A. Matus (1982) Initial phase of dendritic growth: Evidence for the involvement of high molecular weight microtubule-associated proteins (HMWP) before the appearance of tubulin. J. Cell Biol. 92: 589-593.

Bernhardt, R., and A. Matus (1984) Light and electron microscopic studies of the distribution of microtubule-associated protein 2 in rat brain: A difference between dendritic and axonal cytoskeletons. J. Comp. Neurol. 226: 203- 221 .

Binder, L. I., A. Frankfurter, H. Kim, A. Caceres, M. R. Payne, and L. I. Rebhun (1984) Heterogeneity of microtubule-associated protein 2 during rat brain development. Proc. Nati. Acad. Sci. U. S. A. 81: 5613-5617.

Blakemore, C. (1974) Development of functional connexions in the mammalian visual system. Br. Med. Bull. 30: 152-157

Bloom, F. E., T. Ueda, E. Battenberg, and P. Greengard (1979) Immunocytochemical localization, in synapses, of protein $I$, an endogenous substrate for protein kinase in mammalian brain. Proc. Natl. Acad. Sci. U. S. A. 76: 5982-5986.

Bloom, G. S., and R. B. Vallee (1983) Association of MAP 2 with microtubules and intermediate filaments in cultured brain cells. I Cell Biol 96: 15231531. 
Bloom, G. S., T. A. Schoenfeld, and R. B. Vallee (1984). Widespread distribution of the major polypeptide component of MAP 1 (rnicrotubuleassociated protein 1) in the nervous system. J. Cell Biol. 98: 320-330.

Burgoyne, R. D., and R. Cumming (1983) Characterization of microtubuleassociated proteins at the synapse: Absence of MAP 2. Eur. J. Cell Biol. 30: $154-158$.

Byers, D., R. L. Davis, and J. A. Kiger (1981) Defect in cyclic AMP phosphodiesterase due to the dunce mutation of learning in Drosophila melanogaster. Nature 289: 79-81.

Caceres, A., M. R. Payne, L. I. Binder, and O. Steward (1983) Immunocytochemical localization of actin and microtubule-associated protein MAP 2 in dendritic spines. Proc. Natl. Acad. Sci. U. S. A. 80: 1738-1742.

Caceres, A., L. I. Binder, M. R. Payne, P. Bender, L. Redhun, an id O. Sleward (1984a) Differential subcellular localization of tubulin and the microtubuleassociated protein MAP 2 in brain tissue as revealed by immunocytochemistry with monoclonal hybridoma antibodies. J. Neurosci. 4: 394-410.

Caceres, A., G. Banker, O. Steward, L. Binder, and M. Payne (1984b) MAP 2 is localized to the dendrites of hippocampal neurons which develop in culture. Dev. Brain Res. 13: 314-318.

Carlin, R. K., D. J. Grab, R. S. Cohen, and P. Siekevitz (1980) Isolation and characterization of postsynaptic densities from various brain regions: Enrichment of different types of postsynaptic densities. J. Cell Biol. 86: 831-843.

Carlirı, R. K., D. C. Bartell, an id P. Siekevit/ (1983) Idertification of fodrin as a major camodulin-binding protein in postsynaptic density preparations. $\mathrm{J}$. Cell Biol. 96: 443-448.

Cohen, R. S., F. Blomberg, K. Berzins, and P. Siekevitz (1977) The structure of postsynaptic densities isolated from dog cerebral cortex. I. Overall morphology and protein composition. J. Cell Biol. 74: 181-203.

Cragg, B. G. (1967). Changes in visual cortex on first exposure of rats to light. Nature 215: 251-253.

Cragg, B. G. (1972) The development of synapses in cat visual cortex. Invest. Ophthalmol. 11: 377-385

Cragg, B. G. (1975) The development of synapses in kitten visual cortex during visual deprivation. Exp. Neurol. 46: 445-451.

Cumming, R., and R. D. Burgoyne (1983) Compartmentalization of neuronal cytoskeletal proteins. Rev. Biosci. Rep. 3: 997-1006.

Cynader, M., and D. E. Mitchell (1980) Prolonged sensitivity to monocular deprivation in dark-reared cats. J. Neurophysiol. 43: 1026-1040.

Cynader, M. N. Berman, and A. Hein (1976) Recovery of function in cat visual cortex following prolonged deprivation. Exp. Brain Res. 25: 139156.

Daw, N. W., R. K. Rader, and T. W. Robertson (1981) Effect of 6-hydroxydopamine on plasticity of direction selective cells in visual cortex. Soc. Neurosci. Abstr. 7: 673

Daw, N. W., R. K. Rader, T. W. Robertson, and M. Ariel (1983) Effects of 6 hydroxydopamine on visual deprivation in the kitten striate cortex. $\mathrm{J}$ Neurosci. 3: 907-914.

Daw, N. W., T. W. Robertson, R. K. Rader, T. O. Videen, and C. J. Coscia (1984a) Substantial reduction of cortical noradrenaline by lesions of adrenergic pathway does not prevent effects of monocular deprivation $\mathrm{J}$. Neurosci. 4: 1354-1360.

Daw, N. W., T. O. Videen, R. K. Rader, and T. W. Robertson (1984b) Intraventricular injections of 6-OHDA do not necessarily prevent the ocular dominance shifts that usually occur in the visual cortex of kittens after monocular deprivation. Soc. Neurosci. Abstr. 10: 468.

De Carrilli, P., T. Ueda, F. E. Bloom, E. Battenberg, and P. Greengard (1979) Widespread distribution of protein $I$ in central and peripheral nervous systems. Proc. Natl. Acad. Sci. U. S. A. 76: 5977-5981.

De Camilli, P., S. M. Harris, W. B. Huttner, and P. Greengard (1983) Synapsin I (protein I), a nerve terminal-specific phosphoprotein. II. Its specific association with synaptic vesicles demonstrated by immunocytochemistry in agarose-embedded synaptosomes. J. Cell Biol. 96: 1355-1373.

De Camilli, P., P. E. Miller, F. Navone, W. E. Theurkauf, and R. B. Vallee (1984) Distribution of microtubule associatcd protein 2 in the nervous system of the rat studied by immunofluorescence. Neuroscience 12: 819846.

DiPasquale, A. M., J. McGuire, G. Muellmann, and S. J. Wasserman (1976) Microtubule assembly in cultivated Greene melanoma cells is stimulated by dibutyryl adenosine $3^{\prime} ; 5^{\prime}$-cyclic monophosphate or cholera toxin. J. Cell Biol. 71: 735-748.

Fifková, E., and R. J. DeLay (1982) Cytoplastic actin in neuronal processes as a possible mediator of synaptic plasticity. J. Cell Biol. 95: 345-350

Francon, J., A. M. Lennon, A. Fellous, A. Mareck, M. Pierre, and J. Nunez
(1982) Heterogeneity of microtubule-associated proteins and brain developrnent. Eur. J. Biocherr. 129: 465-471.

Friedlander, M. J., L. R. Stanford, and S. M. Sherman (1982) Effects of monocular deprivation on the structure-function relationship of individual neurons in the cat's lateral geniculate nucleus. J. Neurosci. 2: 321-330.

Gilbert, C. D. (1983) Microcircuitry of the visual cortex. Annu. Rev. Neurosci. 6: $217-248$.

Goldering, J. R., B. Gonzalez, J. S. McGuire, Jr., and R. L. Delorenzo (1983) Purification and characterization of a calmodulin-dependent kinase from rat brain cytosol able to phosphorylate tubulin and microtubule-associated proteins. J. Biol. Chem. 258: 12632-12640.

Grab, D. J., R. K. Carlin, and P. Siekevitz (1981) The function of calmodulin in the poslsynaptic densities. II. Presence of a calmodulin-activatable protein kinase activity. J. Cell Biol. 89: 440-448.

Griffith, L. M., and T. D. Pollard (1978) Evidence for actin filament-microtubule interaction mediated by microtubule-associated proteins. J. Cell Biol. 78: 958-965

Guide for the Care and Use of Laboratory Animals (Revised 1978) DHEW Publication No. [NIH] 78-23, Office of Science and Health Reports, DRR/ $\mathrm{NIH}$, Bethesda, MD

Harzog, W., and K. Weber (1978) Fractionation of brain microtubule associ ated proteins. Isolation of two different proteins which stimulate tubulin polymerization in vitro. Eur. J. Biochem. 92: 1-8.

Hofmann, F., J. A. Beavo, P. J. Bechtel, and E. G. Krebs (1975) Comparison of adenosine $3^{\prime}: 5^{\prime}$-monophosphate-dependent protein kinases from rabbit skeletal and bovine heart muscle. J. Biol. Chem. 250: 7795-7801.

Hofmann, F., P. J. Bechtel, and E. G. Krebs (1977) Concentrations of cyclic cAMP-dependent protein kinase subunits in various tissues. J. Biol. Chem. 252: $1441-1447$

Hohmann, A., and O. D. Creutzfeldt (1975) Squint and the development of binocularity in humans. Nature 254: 613-614.

Hubel, D., and T. N. Wiesel (1963). Receptive fields of colls in striatc cortex of very young, visually inexperienced kittens. J. Neurophysiol. 26: 9941002

Hubel, D., and T. N. Wiesel (1970) The period of susceptibility to the physiological effects of unilateral eye closure in kittens. J. Physiol. (Lond.) 206: 419-436.

Huber, G., and A. Matus (1984) Differences in the cellular distributions of two microtubule-associated proteins, MAP 1 and MAP 2, in rat brain. J. Neurosci. 4: 151-160

Itakura, T., T. Kasamatsu, and J. D. Pettigrew (1981) Norepinephrine-containing terminals in kitten visual cortex: Laminar distribution and ultrastructure. Neuroscience 6: 159-175

Izant, J. G., and J. R. Mclntosh (1980) Microtubule-associated proteins: A monoclonal antibody to MAP 2 binds to differentiated neurons. Proc. Natl. Acad. Sci. U. S. A. 77: 2741-2745.

Jahn, R., W. Schiebler, and P. Greengard (1984) A quantitative dot-immunobinding assay for proteins using nitrocellulose membrane filters. Proc. Natl. Acad. Sci. U. S. A. 81: 1684-1687.

Jameson, L., and M. Caplow (1981) Modification of microtubule steady-state dynamics by phosphorylation of microtubule-associated proteins. Proc. Natl. Acad. Sci. U. S. A. 78: 3413-3417.

Jameson, L., T. Frey, B. Zeeberg, F. Dalldorf, and M. Caplow (1980) Inhibition of microtubule assembly by phosphorylation of microtubule-associated proteins. Biochemistry 19: 2472-2479.

Jonsson, G., and T. Kasamatsu (1983) Maturation of monoamine neurotransmitters and receptors in cat occipital cortex during postnatal critical period. Exp. Brain Res. 50: 449-458.

Kandel, E. R., and J. H. Schwartz (1982) Molecular biology of learning: Modulation of transmitter release. Science 218: 433-443

Karbon, E. W., R. S. Duman, and S. J. Enna (1984) GABA ${ }_{B}$ receptors and norepinephrine-stimulated cAMP production in rat brain cortex. Brain Res. 306: $327-332$

Kasamatsu, T. (1979) Involvement of the beta-adrenergic receptor in cortical plasticity. Invcst. Ophthalmol. Vis. Sci. (Suppl. ARVO Abstr.) 18: 135

Kasamatsu, T. (1980) A possible role of cyclic nucleotides in plasticity of visual cortex. Soc. Neurosci. Abstr. 6: 494

Kasamatsu, T., and J. D. Pettigrew (1976) Depletion of brain catecholamines: Failure of ocular dominance shift after monocular occlusion in kittens. Science 194: 206-209.

Kasamatsu, T., and J. D. Pettigrew (1979) Preservation of binocularity after monocular deprivation in the striate cortex of kittens treated with 6 hydroxydopamine. J. Comp. Neurol. 185: 139-162.

Kasamatsu, T., J. D. Pettigrew, and M. Ary (1979) Restoration of visual 
cortical plasticity by local microperfusion of norepinephrine. J. Comp. Neurol. 185: 163-182.

Kasamatsu, T., T. Itakura, and G. Jonsson (1981a) Intracortical spread of exogenous catecholamines: Effective concentration for modifying cortical plasticity. J. Pharmacol. Exp. Ther. 217: 841-850.

Kasamatsu, T., J. D. Pettigrew, and M. Ary (1981b) Recovery from the effects of monocular deprivation: Acceleration with norepinephrine and suppression with 6-hydroxydopamine. J. Neurophysiol. 45: 254-266.

Kasamatsu, T., K. Watabe, E. Scholler, and P. Heggelund (1983) Restoration of neuronal plasticity in cat visual cortex by electrical stimulation of the locus coeruleus. Soc. Neurosci. Abstr. 9: 911.

Kennedy, M. B., and P. Greengard (1981) Two calcium/calmodulin-dependent protein kinases, which are highly concentrated in brain, phosphorylate protein I at distinct sites. Proc. Natl. Acad. Sci. U. S. A. 78: 1293-1297.

Kim, H., L. I. Binder, and J. L. Rosenbaum (1979) The periodic association of MAP 2 with brain microtubules in vitro. J. Cell Biol. 80: 266-276.

Kram, R., and G. M. Tomkins (1973) Pleiotypic control by cyclic AMP: Interaction with cyclic GMP and possible role of microtubules. Proc. Natl. Acad. Sci. U. S. A. 70: 1659-1663.

Leterrier, J. F., L. Rappaport, and J. Nunez (1974) Phosphorylation and aggregation of neurotubulin and associated protein kinase. Mol. Cell. Endocrinol. 1: 65-75.

Leterrier, J. F., R. K. H. Liem, and M. L. Shelanski (1982) Interactions between neurofilament and microtubule-associated proteins: A possible mechanism for intraorganellar binding. J. Cell Biol. 95: 982-986.

Livingstone, M. S., P. P. Sziber, and W. G. Quinn (1984) Loss of calcium/ calmodulin responsiveness in adenylate cyclase of rutabaga, a Drosophila learning mutant. Cell 37: 205-215.

Lohmann, S. M., U. Walter, and P. Greengard (1980) Identification of endogenous substrate proteins for CAMP-dependent protein kinase in bovine brain. J. Biol. Chem. 255: 9985-9992.

Lowry, O. H., N. J. Rosebrough, A. L. Farr, and R. J. Randall (1951) Protein measurement with the Folin phenol reagent. J. Biol. Chem. 193: 265-275.

Matus, A., R. Bernhardt, and T. H. Jones (1981) High molecular weight microtubule-associated proteins are preferentially associated with dendritic microtubules in brain. Proc. Natl. Acad. Sci. U. S. A. 78: 3010-3014

Matus, A., M. Ackermann, G. Pehling, H. R. Byers, and K. Fujiwara (1982) High actin concentration in brain dendritic spines and postsynaptic den sities. Proc. Natl. Acad. Sci. U. S. A. 79: 7590-7594.

Miller, P., U. Walter, W. E. Theurkauf, R. B. Vallee, and P. De Camilli (1982) Frozen tissue sections as an experimental system to reveal specific binding sites for the regulatory subunit of type II cAMP-dependent protein kinase in neurons. Proc. Nati. Acad. Sci. U. S. A. 79: 5562-5566.

Movshon, J. A., and R. C. Van Sluyters (1981) Visual neural development. Annu. Rev. Psychol. 32: 477-522.

Mower, G. D., J. L. Burchfiel, and F. H. Duffy (1981a) The effects of dark rearing on the development of plasticity of the LGN. Dev. Brain Res. 1: 418-424.

Mower, G. D., D. Berry, J. L. Burchfiel, and F. H. Duffy (1981b) Comparison of the effects of dark-rearing and binocular suture on development and plasticity of cat visual cortex. Brain Res. 220: 225-267.

Mower, G. D., W. G. Christen, and C. J. Caplan (1983) Very brief visual experience eliminates plasticity in the cat visual cortex. Science 221: 178180.

Murphy, D. B., and G. G. Borisy (1975) Association of high-molecular-weight proteins with microtubules and their role in microtubule assembly in vitro. Proc. Natl. Acad. Sci. U. S. A. 72: 2696-2700.

Murphy, D. B., K. A. Johnson, and G. G. Borisy (1977) Role of tubulinassociated proteins in microtubule nucleation and elongation. J. Mol. Biol. 117: 33-52.

Murthy, A. S. N., and M. Flavin (1983) Microtubule assembly using the microtubule-associated protein MAP 2 prepared in defined states of phosphorylation with protein kinase and phosphatase. Eur. J. Biochem. 137: $37-46$.

Nathanson, J. A. (1977) Cyclic nucleotides and nervous system function. Physiol. Rev. 57: 157-256.

Neville, D. M., Jr. (1971) Molecular weight determinations of protein-dodecyl sulfate complexes by gel electrophoresis in a discontinuous buffer system. J. Biol. Chem. 246: 6328-6334.

Nishida, E., T. Kuwaki, and H. Sakai (1981) Phosphorylation of microtubuleassociated proteins (MAPs) and $\mathrm{pH}$ of the medium control interaction between MAPs and actin filaments. J. Biochem. 90: 575-578.

Paradiso, M. A., M. F. Bear, and J. D. Daniels (1983) Effects of intracortical infusion of 6-hydroxydopamine on the response of kitten visual cortex to monocular deprivation. Exp. Brain Res. 51: 413-422.
Petrig, B., G. Baumgartner, and M. Anliker (1981) Development of stereopsis and cortical binocularity in human infants: Electrophysiological evidence. Science 213: 1402-1405

Pettigrew, J. D., and T. Kasamatsu (1978) Local perfusion of noradrenaline maintains visual cortical plasticity. Nature 271: 761-763.

Pomerantz, A. H., S. A. Rudolph, B. E. Haley, and P. Greengard (1980) Photoaffinity labeling of a protein kinase from bovine brain with 8-azidoadenosine--3': $5^{\prime}$-monophosphate. Biochemistry $14: 3858-3862$.

Pytela, R., and G. Wiche (1980) High molecular weight polypeptides $(270,000-240,000)$ from cultured cells are related to hog brain microtubulc associated proteins but copurify with intermediate filaments. Proc. Natl. Acad. Sci. U. S. A. 77: 4808-4812

Rakic, P. (1974) Neurons in thesus monkey visual cortex: Systematic relation between time of origin and eventual disposition. Science 183: 425-427.

Rakic, P. (1977) Prenatal development of the visual system in rhesus monkey. Philos. Trans. R. Soc. Lond. (Biol.) 278: 245-260.

Rangel-Aldao, R., J. W. Kupiec, and O. M. Rosen (1979) Resolution of the phosphorylated and dephosphorylated CAMP-binding proteins of bovine cardiac muscle by affinity labeling and two-dimensional electrophoresis. $J$. Biol. Chem. 254: 2499-2508.

Rappaport, L., J. F. Letterier, and J. Nunez (1972) Non phosphorylation in vitro of the $6 S$ tubulin from brain and thyroid tissue. FEBS Lett. 26: 349352.

Rappaport, L., J. F. Letterier, A. Virion, and J. Nunez (1976) Phosphorylation of microtubule-associated proteins. Eur. J. Biochem. 62: 539-549.

Reisine, T. D., J. I. Nagy, K. Beaumont, H. C. Fibiger, and H. I. Yamamura (1979) The localization of receptor binding sites in the substantia nigra and striatum of the rat. Brain Res. 177: 241-252.

Rice, R. V., P. R. Roslansky, N. Pascoe, and S. M. Houghton (1980) Bridges between microtubule and neurofilament visualized by stereoelectron microscopy. J. Ultrastruct. Res. 71: 303-310.

Richmond, P. G., and C. B. Klee (1978) Interaction of ${ }^{125}$-labeled $\mathrm{Ca}^{2+}$ dependent regulator protein with cyclic nucleotide phosphodiesterase and its inhibitory protein. J. Biol. Chem. 253: 6323-6326.

Roisen, F. J., and R. A. Murphy (1973) Neurite development in vitro. II. The role of microfilaments ad microtubules in dibutyryl adenosine $3^{\prime} 5^{\prime}$-cyclic monophosphate and nerve growth factor stimulated maturation. J. Neurobiol. 4: 397-412.

Roisen, F. J., R. A. Murphy, and W. G. Braden (1972) Neurite development in vitro. I. The effects of adenosine $3^{\prime}: 5^{\prime}$-cyclic monophosphate (cyclic AMP). J. Neurobiol. 3: 347-368.

Rose, S. P. R., A. K. Sinha, and A. Jones-Lecointe (1976) Synthesis of tubulin-enriched fraction in rat visual cortex is modulated by dark-rearing and light-exposure. FEBS Lett. 65: 135-139.

Sarkar, D., J. Erlichman, and C. S. Rubin (1984) Identification of a calmodulinbinding protein that co-purifies with the regulatory subunit of brain protein kinase II. J. Biol. Chem. 259: 9840-9846.

Sattilaro, R. F., W. L. Dentler, and E. L. LeCluyse (1981) Microtubuleassociated proteins and the organization of actin filaments in vitro. J. Cell Biol. 90: 467-473.

Schulman. H. (1984) Differential phosphorylation of MAP 2 stimulated by calcium-calmodulin and cyclic AMP. Mol. Cell. Biol. 4: 1175-1178.

Seldon, S. C., and T. D. Pollard (1983) Phosphorylation of microtubuleassociated proteins regulates their interaction with actin filaments. J. Biol. Chem. 258: 7064-7071.

Shaw, C., M. C. Needler, M. Wilkinson, C. Aoki, and M. Cynader (1985) Alterations in receptor number, affinity and laminar distribution in cal visual cortex during the critical period. Prog. Neuropsychopharmacol. Biol. Psychiatry, in press.

Shapley, R. M., and Y. T. So (1980) Is there an effect of monocular deprivation on the proportions of $X$ and $Y$ cells in the cat LGN? Exp. Brain Res. 39: 41-48.

Sherman, S. M., and P. D. Spear (1982) Organization of visual pathways in normal and visually deprived cats. Physiol. Rev. 62: 738-855.

Sheterline, P. (1977) Phosphorylation of pig brain microtubule proteins. General properties and partial characterization of endogenous substrate and CAMP-dependent protein kinase. Biochem. J. 168: 533-539.

Shigekawa, B. I., and R. W. Olsen (1975) Resolution of CAMP stimulated protein kinase from polymerization-purified brain microtubules. Biochem. Biophys. Res. Commun. 63: 455-462.

Sloboda, R. D., S. A. Rudolph, J. L. Rosenbaum, and P. Greengard (1975) Cyclic AMP dependent endogenous phosphorylation of a microtubuleassociated protein. Proc. Natl. Acad. Sci. U. S. A. 72: 177-181

Sloboda, R. D., W. L. Dentler, and J. L. Rosenbaum (1976) Microtubule- 
associated proteins and the stimulation of tubulin assembly in vitro. Biochemistry 15: 4497-4505.

Snyder, J. A., and J. R. Mclntosh (1976) Biochemistry and physiology of microtubules. Annu. Rev. Biochem. 45: 699-720.

Soifer, D., A. Lazlo, K. Mack, J. Scotto, and L. Siconolfi (1975) The association of a cAMP-dependent protein kinase activity with mcirotubule protein. Ann. N. Y. Acad. Sci. 253: 598-610.

Theurkauf, W. E., and R. B. Vallee (1982) Molecular characterization of the cAMP-dependent protein kinase bound to microtubule-associated protein 2. J. Biol. Chem. 257: 3284-3290.

Theurkauf, W. E., and R. B. Vallee (1983) Extensive cAMP-dependent and cAMP-independent phosphorylation of microtubule-associated protein 2. J. Biol. Chem. 258: 7883-7886.

Timney, B., D. E. Mitchell, and F. Griffin (1978) The development of vision in cats after extended periods of dark-rearing. Exp. Brain Res. 31: 547-560.

Timney, B., D. E. Mitchell, and M. Cynader (1980) Behavioral evidence for prolonged sensitivity to effects of monocular deprivation in dark-reared cats. J. Neurophysiol. 43: 1041-1054.

Towbin, H., T. Staehelin, and J. Gordon (1979) Electrophoretic transfer of protein from polyacrylamide gels to nitrocellulose sheets: Procedure and some application. Proc. Natl. Acad. Sci. U. S. A. 76: 4354-4356.

Toyo-oka, T., T. Shimizu, and T. Masaki (1978) Inhibition of proteolytic activity of calcium-activated neutral protease by leupeptin and antipain. Biochem. Biophys. Res. Cormmurı. 82: 484-491.

Ueda, T., and P. Greengard (1977) Adenosine $3^{\prime}: 5^{\prime}$-monophosphate-regulated phosphoprotein system of neuronal membranes. I. Solubilization, purification and some properties of an endogenous phosphoprotein. J. Biol. Chem. 252: 5155-5163.
Ueda, T., P. Greengard, K. Berzins, R. S. Cohen, F. Blomberg, D. J. Grab, and P. Siekevitz (1979) Subcellular distribution in cerebral cortex of two proteins phosphorylated by a cAMP-dependent protein kinase. J. Cell Biol. 83: $308-319$

Vallee, R. B., M. J. DiBartolomeis, and W. E. Theurkauf (1981) A protein kinase bound to the projection portion of MAP 2 (microtubule-associated protein 2). J. Cell Biol. 90: 568-576.

Valverde, F. (1967) Apical dendritic spines of the visual cortex and light deprivation in the mouse. Exp. Brain Res. 3: 337-352.

Valverde, F. (1971) Rate and extent of recovery from dark-rearing in the visual cortex of the mouse. Brain Res. 33: 1-11.

Walaas, S. I., and P. Greengard (1984) DARPP-32, a dopamine- and adenosine $3^{\prime}: 5^{\prime}$-monophosphate-regulated phosphoprotein enriched in dopamine-innervated brain regions. I. Regional and cellular distribution in the rat brain. J. Neurosci. 4: 84-98.

Walter, U., P. Kanof, H. Schulman, and P. Greengard (1978) Adenosine $3^{\prime}: 5^{\prime}$-monophosphate receptor proteins in mammalian brain. J. Biol. Chem. 253: 6275-6280

Wiesel, T. N., and D. Hubel (1963a) Single-cell responses in striate cortex of kittens deprived of vision in one eye. J. Neurophysiol 26: 1003-1017.

Wiesel, T. N., and D. Hubel (1963b) Effects of visual deprivation on morphology and physiology of cells in the cat's lateral geniculate body. J. Neurophysiol. 26: 978-993.

Wiesel, T. N., and D. Hubel (1965) Extent of recovery from the effects of visual deprivation in kittens. J. Neurophysiol. 28: 1060-1072.

Yamamoto, H., K. Fukunaga, E. Tanaka, and E. Miyamoto (1983) $\mathrm{Ca}^{2+}$ - and calmodulin-dependent phosphorylation of microtubule-associated protein 2 and factor, and inhibition of microtubule assembly. J. Neurochem. 41: $1119-1125$. 